\title{
Fatigue Strength of Rivet Resistance Spot Welding Technique in Comparison with Self-Piercing Riveting for Multi-material Body-in-White Structure
}

\author{
Daniel Heidrich, Fan Zhang, and Xiangfan Fang
}

Submitted: 20 August 2020 / Revised: 15 February 2021 / Accepted: 5 March 2021 / Published online: 5 May 2021

\begin{abstract}
Cost-efficient multi-material design requires suitable joining techniques, ideally with low investment cost by re-using existing assembling lines. The recently developed resistance rivet spot welding (RRSW) technique combines mechanical joining with spot welding and enables cost-efficient joining of aluminum (Al) to steel for multi-material body-in-white structures. Here, the static and fatigue strengths of different hybrid Alsteel specimens made by RRSW were measured and compared to other state-of-the-art joining techniques, such as self-piercing riveting (SPR) and RSW. The static strength of RRSW matched or exceeded that of SPR regardless of the sheet thickness, whereas the fatigue strength of the RRSW joints showed a strong dependency on the thickness of the steel sheets. For thinner steel sheets, the fatigue of the RRSW-joined metal sheets was lower in comparison with SPR. Fatigue cracks were initiated in thin steel sheets around the weld nugget. By contrast, for thicker steel sheets, the fatigue strength of RRSW matched or exceeded that of SPR. With a thicker material combination of $1.5 \mathrm{~mm}$ steel and $1.0 \mathrm{~mm} \mathrm{Al}$, fatigue cracks occurred only in the Al sheet in both SPR and RRSW. For suitable steel sheet thickness, RRSW is thus a durable technique to join steel and Al.
\end{abstract}

Keywords aluminum-steel hybrid specimen, car body engineering, H-specimen, hybrid joining, multi-material design, rivet resistance spot welding, self-piercing riveting

\section{Introduction}

Lightweight design is a key technology for reducing the fuel consumption of vehicles with conventional combustion engines as well as extending the range of electric vehicles. Due to the higher cost of lightweight materials, such as fiber-reinforced plastics or aluminum (Al) alloys, in comparison with steel, a multi-material car body structure consisting of steel and Al can be a compromise in terms of weight saving and cost reduction. To join dissimilar materials, such as $\mathrm{Al}$ and steel, a wide range of innovative joining techniques have been developed, such as self-piercing riveting (SPR) (Ref 1-4), resistance element welding (REW) (Ref 3, 5), friction element welding (FEW) (Ref 3), joining with flow drill screws (FDS) (Ref 3-6), or highspeed bolt joining (Ref 3 ).

SPR is currently the most widely used mechanical joining technique in the automotive industry for joining $\mathrm{Al}$ or $\mathrm{Al}$ to steel (Ref 1, 4, 7, 8). Besides the quasi-static properties reported in Ref 9-11, fatigue properties are essential for automotive structure development. The fatigue behavior of SPR for joining

Daniel Heidrich, Fan Zhang, and Xiangfan Fang, Institute of Automotive Lightweight Design, University of Siegen, Breite Strasse 11, 57076 Siegen, Germany. Contact e-mails: Daniel.Heidrich@unisiegen.de, Fan.Zhang@uni-siegen.de, and Xiangfan.Fang@unisiegen.de.

Al sheets (Ref 12-15) or Al and fiber-reinforced plastics (Ref 16) has already been analyzed in several studies.

In Ref $13,14,17$ and 18, the fatigue behavior of different joining techniques, such as resistance spot welding (RSW), SPR, and clinching, for Al-alloys was investigated. In Ref 13 and 14, SPR showed the best mechanical properties under fatigue load in comparison with spot welding and flow drill screws. The SN-curve inclination for SPR and flow drill screws ranged between $\mathrm{k}=5-7.6$, whereas welded joints showed a steeper inclination of $\mathrm{k}=4$ 4.7-5.6. In Ref 17, the fatigue behavior of SPR-joined Al sheets and spot-welded Al sheets was investigated. The Al sheets joined with SPR showed twice the fatigue life in comparison with spot-welded Al specimens. Similar results were obtained in Ref 18 , where Al spot welding showed $25-100 \%$ lower fatigue life in comparison with SPR.

In Ref 19, spot welding and SPR on low carbon steel and high-strength steel showed that the static strength of spotwelded joints exhibits the SPR, whereas the SPR joints revealed better fatigue performance. In Ref 20, fatigue tests on dual phase steel using single-point lap-shear specimens showed a higher fatigue life for SPR in comparison with a spotwelded specimen as well.

Together, these studies demonstrated that riveted joints tend to exhibit a higher fatigue life than spot-welded joints, even if the static strength of the riveted joints is lower than the spotwelded joints. According to Ref (13), the work-hardening effect due to the SPR process increases the yield strength of the joined materials, which also leads to increased fatigue properties. By contrast, annealing in the spot-welding process reduces the yield strength, and thus the fatigue strength of the spot-welded joints decreases. This leads to higher inclinations of the SNcurve and consequently lower durability at higher load cycles (see also Ref 14 and 15).

Given that fatigue investigations with single-point specimens do not take load redistribution into account (Ref 21), 
multi-point specimens for SPR and spot welding were investigated in Ref 22, 23, and 24. In multi-point specimens, load redistribution occurs; that is, if one joint is damaged, a neighboring joint may carry more load. Therefore, in Ref 23 and 24, a 2-point lap shear specimen was introduced. Furthermore, if thin metal sheets are joined, the sheet metals of the lap shear specimens tend to be bended when a tensile load is applied. This leads to a mixed load situation of shear and pullout tension. The fatigue behavior of a flat specimen can thus not be directly transferred to the fatigue behavior of a component.

Consequently, more complex shaped specimens with several joining elements must be considered. The 10-point H-specimen was developed for spot welding (Ref 25) and later used for fatigue investigations of SPR (Ref 22, 23) after small geometrical adaptions with regard to flange lengths were conducted. These H-specimens can be implemented for shear or peeling tests. In Ref 23 and 24, a SPR and a spot-welded Hspecimen (1.5 mm HSLA steel H280 LAD) were tested in a tension-tension fatigue test $(\mathrm{R}=0.1)$. For the SPR shear and peeling $\mathrm{H}$-specimen, the $\mathrm{SN}$-curve inclination was $\mathrm{k}=6.2$, whereas for the spot-welded $\mathrm{H}$-specimen, $\mathrm{k}=5.3$ was determined. Fatigue tests with a spot-welded peeling $\mathrm{H}$ specimen made of mild steel DX54 and HSLA steel CR320 LA (both $1.8 \mathrm{~mm}$ ) exhibited an SN-curve inclination of $\mathrm{k}=3.1-4.7$. Both investigations showed that peeling stresses reduce fatigue life in comparison with shear stresses, suggesting that the fatigue strength of SPR exceeds the fatigue strength of spot welds and confirming the results obtained with flat lap shear specimens (Ref 13, 14, 17, 18, 20).

Compared to SPR, RSW is still the most dominant joining technique in the automotive industry because of its low cost and high quality (Ref 7). Due to the requirements of a flexible joining technique, using the same joining technique for an allsteel body-in-white structure and a steel-Al mixed-material structure, a new resistance rivet spot welding (RRSW) method was developed (Ref 26). RRSW is a combined mechanical joining and spot-welding method in which a rivet element with the characteristics shown in Fig. 1(a) (details see Ref 26) has to be punched into an Al sheet metal directly after the Al sheet forming. The rivet forming or punching process is shown in Fig. 1(b). At the end of the rivet punching process, a form-fit between the $\mathrm{Al}$ and the steel insert is created. This steel insert punched into Al-sheet metal works as a welding adapter to join the $\mathrm{Al}$ sheet to another steel sheet. The results of the welding of an Al sheet to a steel sheet metal can be seen in Figure 1.

RRSW has several advantages in comparison with SPR. First, the flange width for RRSW is smaller than for SPR. This is important given that the package space for lightweight design must not be sacrificed. Secondly, due to the $1 \mathrm{~mm}$ height of the rivet head, a distinct gap between the $\mathrm{Al}$ and steel component is created [see Fig. 1(c)]. This gap enables the complete wetting of the steel and Al parts with cathodic dip paint (Ref 26). Thus, the resistance against galvanic corrosion is sufficient without using adhesives between the steel and $\mathrm{Al}$, which is necessary for parts joined with SPR (Ref 1). Quasi-static lap shear tests in Ref 26 showed that for seven of the nine considered material and thickness combinations, the strength of RRSW is superior to that of SPR. However, the fatigue strength of sheet metals joined using RRSW has not been investigated and is thus the aim of this work.

\section{Experimental Setup}

\subsection{Materials and Specimen Geometries}

Based on the previous static test results in Ref 26, fatigue tests were conducted in this work to extend the characterization of RRSW. For this purpose, the two most critical material combinations according to Ref (26) were chosen for this study, which are the combination of $0.8 \mathrm{~mm}$ CR340 steel with $1.0 \mathrm{~mm}$ Al 6016 and $1.5 \mathrm{~mm} \mathrm{CR340} \mathrm{steel} \mathrm{with} 1.0 \mathrm{~mm} \mathrm{Al} \mathrm{6016.} \mathrm{The}$ first one is defined as material combination $\mathrm{C} 1$ and the second one as $\mathrm{C} 2$ in this work. C1 was selected for fatigue investigations, as the static test results of this material combination previously exhibited the lowest performance out of 9 different material combinations. Additionally, material combination $\mathrm{C} 2$ was investigated to address the fact that fatigue load is usually more severe for thinner sheet metals. The mechanical properties of both materials are summarized in Table 1. The rivet was made of the mild steel S355, which offers high formability and good weldability.

To conduct the fatigue tests, four different specimen types were used, as shown in Figure 2. Flat lap-shear specimen with one (a) and two (b) joining elements, and an H-specimen with 10-points that can be loaded in a shear (c) or peeling (d)

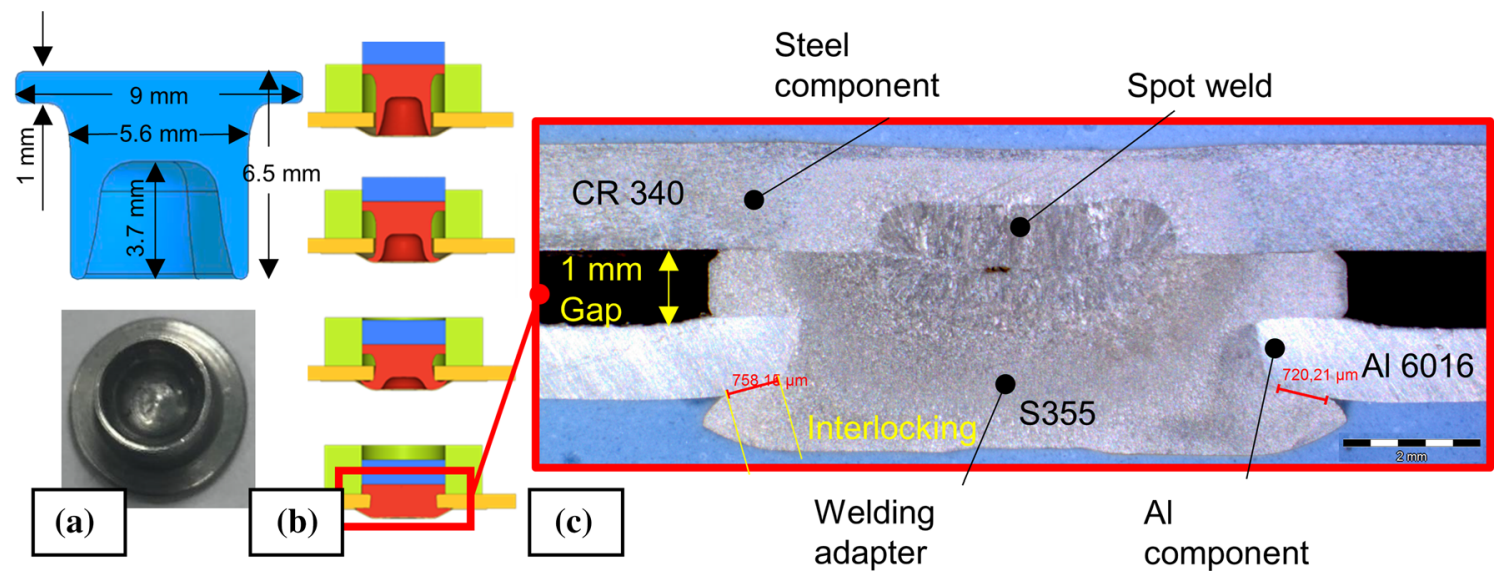

Fig. 1 (a) The geometrical characteristics of the rivet element used as welding adapter (b) Forming process of the steel welding adapter (c) A micro-section of RRSW connection with $1 \mathrm{~mm}$ characteristic gap between $\mathrm{Al}$ and steel to avoid galvanic corrosion 
Table 1 Mechanical properties of steel and Al sheet metals used in the experiments (Ref 27)

\begin{tabular}{lccc}
\hline Material & Thickness, mm & Yield stress, MPa & Ultimate tensile stress, MPa \\
\hline CR340 LA + Z & $0.8 / 1.5$ & $340-420$ & $410-510$ \\
Al 6016 T4 & 1.0 & 135 & 247 \\
\hline
\end{tabular}

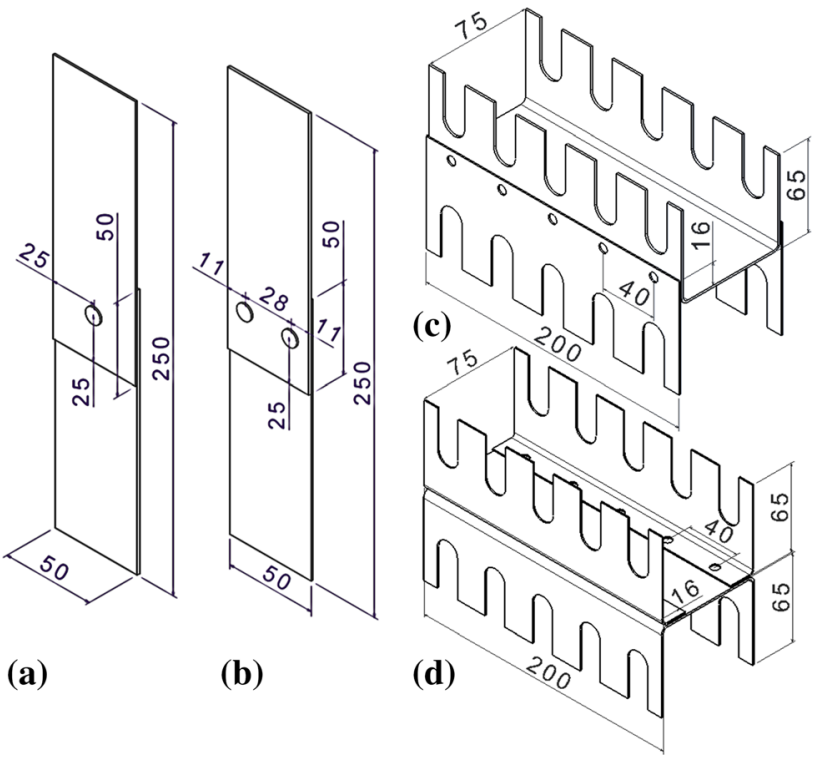

Fig. 2 (a) 1-point lap-shear specimen, (b) 2-point lap-shear specimen, (c) 10-point shear H-specimen, and (d) 10-point peeling H-specimen

direction. The force-controlled fatigue tests were conducted under tension-tension load ratio $(\mathrm{R}=0)$.

The dimensions of the spot-welded 1-point lap-shear specimen are defined in DIN EN ISO 14324 (Ref 21). However, for the SPR study, the width, span length, and overlap of the two sheet metals must be increased to guarantee sufficient space for joining with SPR. To avoid any size effect, the modified specimen size for SPR was also used for RRSW, as shown in Fig. 2(a).

As mentioned in section 1, a 1-point specimen cannot exhibit any load redistribution effect during the fatigue test when the joint is damaged. Therefore, the 2-point specimen specified in Ref 24 was used as well. To achieve an improved comparability to the situation in a real vehicle structure, the $\mathrm{H}$ specimen with 10 joining points was chosen, which was developed for two loading conditions: one for shear (Figure 2c) and another for peeling (Figure 2d) load. Both specimen types were designed and manufactured according to DIN EN ISO 18592 specifications (Ref 25).

Using the two steel and one Al materials, a test matrix with two material combinations $\mathrm{C} 1$ and $\mathrm{C} 2$ for the four specimen types was created, as presented in Table 2.

\subsection{Manufacturing of SPR Specimens}

The SPR lap-shear specimens with one and two rivets were manufactured with a handheld HRB5 electro-hydraulic rivet setter (Henrob; New Hudson, MI, USA). To guarantee high reproducibility, a positioning aid was used. The rivet elements with a height of $5.5 \mathrm{~mm}$ and a diameter of $5.0 \mathrm{~mm}$ were stamped through the Al sheet into the die-sided steel sheet. Therefore, the pipped die B1 DZ 0902050 by Henrob was used.

The quality of the flat shear and complex H-specimens joined with SPR was checked by microscopic analysis. Figure 3 shows the micro-sections of the SPR connection of the thickness combination $\mathrm{C} 1(0.8 \mathrm{~mm}$ steel and $1 \mathrm{~mm} \mathrm{Al})$ and C2 (1.5 mm steel and $1 \mathrm{~mm} \mathrm{Al})$.

According to Ref 11, the head height of the rivet, the bottom sheet thickness, and the interlock distance are important characteristics of the SPR connection. A head height between $0.3 \mathrm{~mm}$ and $-0.5 \mathrm{~mm}$ (negative head height means that the rivet head is below the surface of the top sheet) is recommended, which is also in good agreement with the guidelines of Henrob. According to Henrob specifications, the minimum interlock distance must be $0.2 \mathrm{~mm}$ and the bottom sheet thickness is recommended to be at least $0.2 \mathrm{~mm}$.

With the maximum riveting force of the rivet setter $(50 \mathrm{kN})$ and the chosen rivet element, a head height of $0.15 \mathrm{~mm}$ for $\mathrm{C} 1$ and $0.2 \mathrm{~mm}$ for $\mathrm{C} 2$ could be realized. For both thickness combinations, the interlock distance exceeded the minimum required interlock distance of $0.2 \mathrm{~mm}$ (Ref 28). However, Figure $3 \mathrm{a}$ shows that the remaining bottom sheet thickness was below the recommendations. As the remaining bottom sheet thickness is mandatory for corrosion and NVH behavior, although it has a minor influence on joint strength, the bottom sheet penetration for material combination $\mathrm{C} 1$ is acceptable. Therefore, the rivet sizes and the riveting parameters mentioned above were used for all four specimen types in this study, including the $\mathrm{H}$-specimens for shear and peeling. Due to poor accessibility with the $\mathrm{C}$-frame of the handheld rivet setter, the $\mathrm{H}$-specimens for peeling were manufactured at the technical center of the rivet machine manufacturer, Henrob, with the same riveting parameters as the other specimens.

\subsection{Manufacturing of Resistance Rivet Spot Welding (RRSW) Specimens}

To manufacture the RRSW lap-shear specimens with one and two welding points, based on the description in Figure 1, holes with a $6.5 \mathrm{~mm}$ diameter were punched into the Al sheet (Figure 4a). Subsequently, the welding adapter, a steel rivet element made of mild steel S355 with a $6.5 \mathrm{~mm}$ rivet height and a $5.6 \mathrm{~mm}$ nominal diameter [see Fig. 1(a)] was stamped into the hole of the $\mathrm{Al}$ sheet with a forming force of $50 \mathrm{kN}$ per rivet (Figure $4 \mathrm{~b}$ ). In the next step, the $\mathrm{Al}$ sheet including the steel welding adapter and the steel sheet were positioned using a fixture (Figure 4c) and spot welded (Figure 4d) using the stationary spot welding machine PMS 14-6 MF (Dalex; Wissen, Germany).

A welding parameter optimization was carried out on the simple one-point lap shear test samples, since the fatigue performance of the spot weld is highly influenced by the welding quality. If the welding heat input in the $\mathrm{Al}$ around the 
Table 2 Test matrix for fatigue test of SPR and RRSW joining techniques with four different specimen types and two material combinations

\begin{tabular}{|c|c|c|c|}
\hline & 1-point specimen & H-specimen shear & H-specimen peel \\
\hline Self-piercing & & Material combination $\mathrm{C} 1=0.8 \mathrm{~mm} \mathrm{CR} 340+1.0 \mathrm{~mm} \mathrm{Al} 6016$ & \\
\hline riveting (SPR) & & Material combination C2 $=1.5 \mathrm{~mm} \mathrm{CR} 340+1.0 \mathrm{~mm} \mathrm{Al} 6016$ & \\
\hline Resistance rivet & & Material combination $\mathrm{C} 1=0.8 \mathrm{~mm} \mathrm{CR} 340+1.0 \mathrm{~mm} \mathrm{Al} 6016$ & \\
\hline spot welding (RRSW) & & Material combination $\mathrm{C} 2=1.5 \mathrm{~mm} \mathrm{CR} 340+1.0 \mathrm{~mm} \mathrm{Al} 6016$ & \\
\hline
\end{tabular}
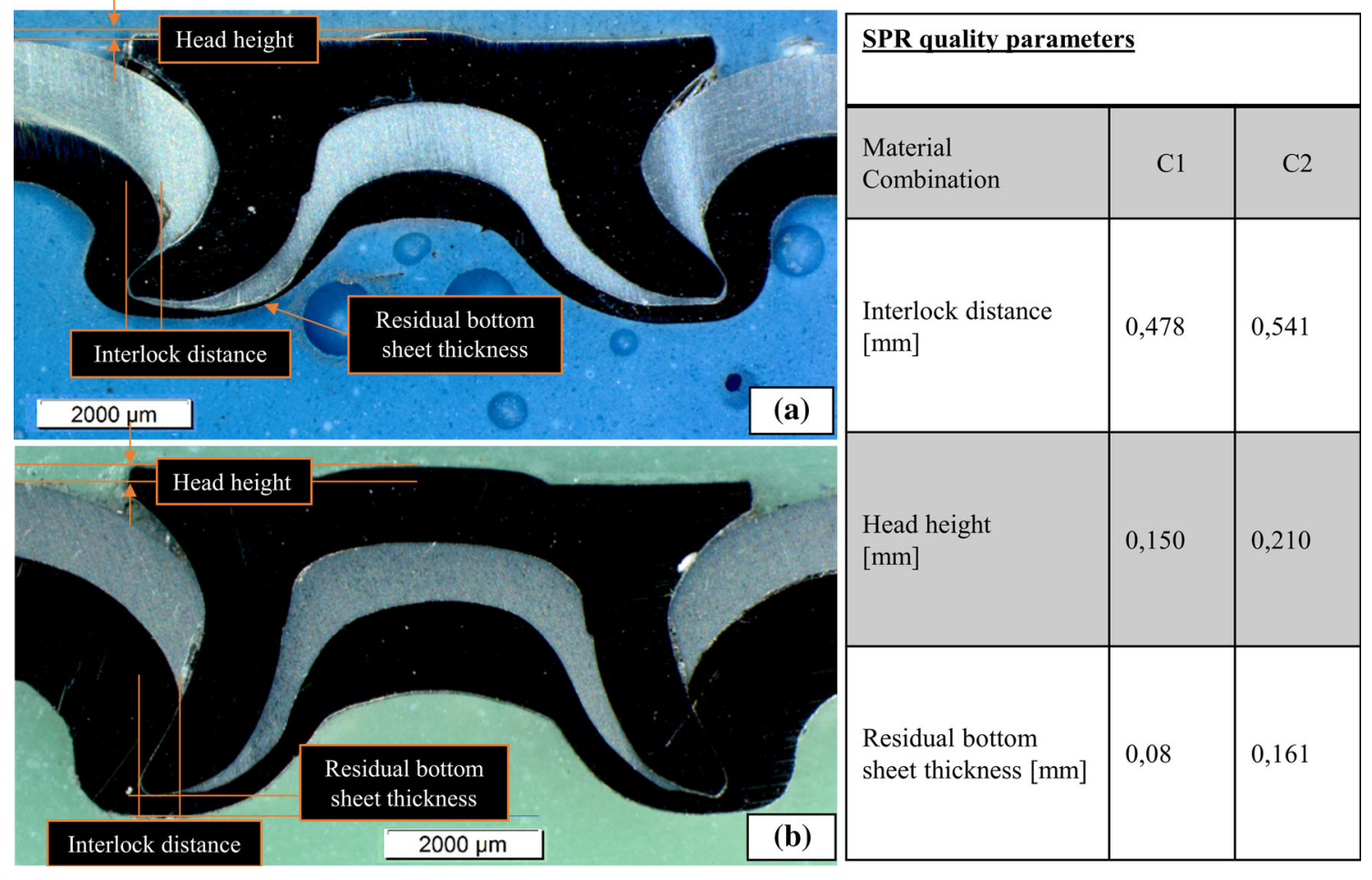

Fig. 3 Micro-section of self-piercing riveting (SPR) with thickness combination (a) C1 (1 mm Al $6016+0.8 \mathrm{~mm} \mathrm{CR340} \mathrm{LA)} \mathrm{and} \mathrm{(b)} \mathrm{C2} \mathrm{(1.5}$ $\mathrm{mm}+\mathrm{CR} 340 \mathrm{LA})$ to evaluate the joining quality; recommended tolerances: interlock distance $>0.2 \mathrm{~mm}$, head height $0.3 \mathrm{~mm}$ to $-0.5 \mathrm{~mm}$

steel welding adapter is too high, the Al will be annealed or even melted, which lowers the fatigue limit of the material. By contrast, too-low welding heat input in the steel welding adapter might cause a poor weld nugget diameter, which can also lower the fatigue strength of the connection. Thus, during the spot-welding parameter optimization, the weld nugget size, the grade of Al melting, and the connection behavior in the chisel test were taken into consideration. The optimized spotwelding parameters for each specimen type are shown in Table 3. Since the H-specimens must be spot welded by the welding company, Dalex, due to the complex shape with a different welding machine, the $\mathrm{H}$-specimen welding parameters were slightly different from the one- and two-point specimens.

In addition to the chisel test, the quality of the RRSW joints was also investigated using micro-sections, as shown in Fig. 1(c). The targeted $1 \mathrm{~mm}$ gap between the $\mathrm{Al}$ and steel sheets, which allows for a full wetting with fluid in a cathodic dip painting process, is precisely achieved. The interlocking of the steel rivet in the Al sheet is around $0.75 \mathrm{~mm}$, which is nearly twice the interlock distance, which was measured for SPR. The nugget size of $4.6 \mathrm{~mm}$ for material combination $\mathrm{C} 1$ and $5.0 \mathrm{~mm}$ for material combination $\mathrm{C} 2$ is sufficient according to welding guidelines $(\mathrm{d} \approx 4-5 \sqrt{t}, \mathrm{t}$ : minimum sheet metal thickness).

To insert the steel rivet into the $\mathrm{Al}$ component of the $\mathrm{H}$ specimen, a C-frame tool was designed and manufactured, which enabled flexible accessibility for complex-shaped specimens and components. Using a hydraulic hand pump, a rigid punch is actuated, which punches the steel rivets with a riveting force of $50 \mathrm{kN}$ into the pre-drilled hole of the Al profile. Afterwards, the steel and the $\mathrm{Al}$ profiles of both the $\mathrm{H}$-specimen types, shown in Fig. 5(a) and (b), were joined by RRSW with a Dalex PL 100 machine at the technical center of the welding machine manufacturer Dalex.

\subsection{Fatigue Test Equipment}

All fatigue tests of the 2-point shear specimens and $\mathrm{H}-$ specimens were conducted using the Sincotec PowerSwing resonance pulsator (SincoTec; Clausthal-Zellerfeld, Germany) (Figure 6). The test machine was equipped with a $12.5 \mathrm{kN}$ load cell for the flat specimen with relatively low force amplitudes (Figure 6a, b), whereas for the H-specimens, a $100 \mathrm{kN}$ load cell was used (Figure 6c). 

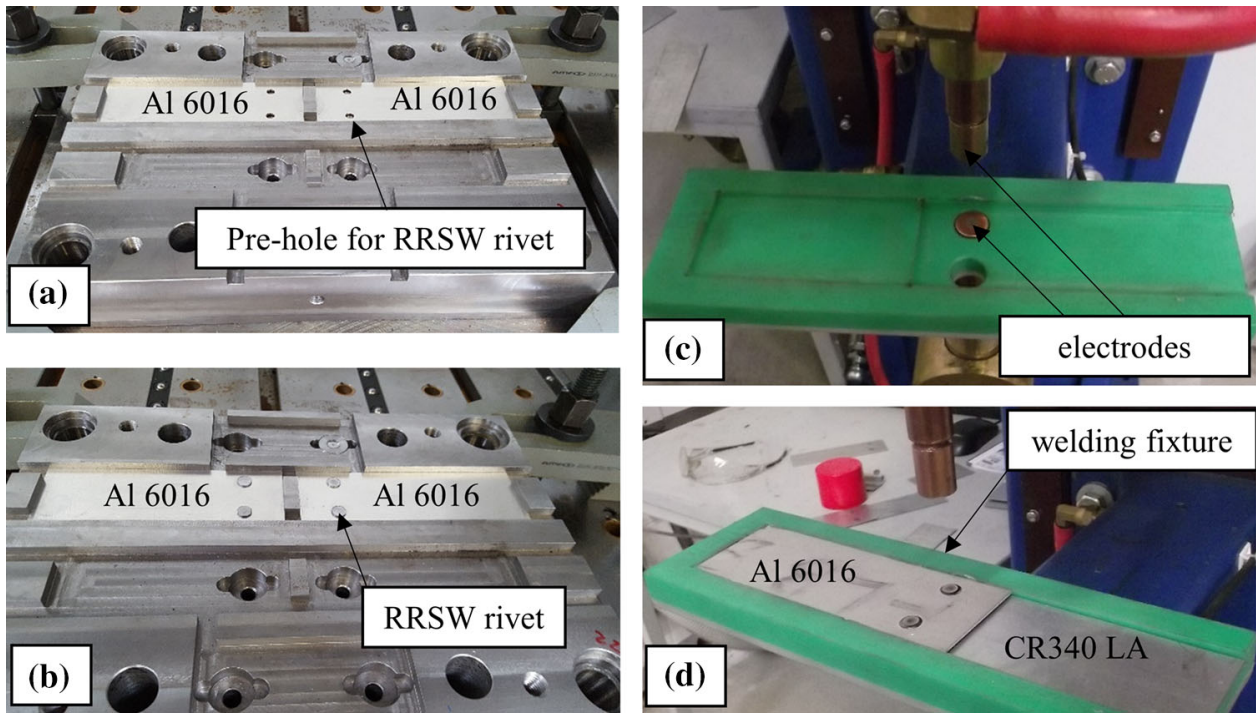

Fig. 4 Specimen manufacturing process of resistance rivet spot welding (RRSW): inserting Al 6016 sheets with (a) a pre-punched hole, (b) stamping the welding adapter into the hole, (c) using a positioning aid to fix for spot welding and (d) spot welding of steel welding adapter and steel sheet

Table 3 Spot welding parameters for rivet resistance spot welding

\begin{tabular}{lcccccccc}
\hline $\begin{array}{l}\text { Specimen } \\
\text { type }\end{array}$ & $\begin{array}{c}\text { Steel sheet } \\
\text { thickness, } \mathbf{m m}\end{array}$ & $\begin{array}{c}\text { Squeeze } \\
\text { time, } \mathbf{m s}\end{array}$ & $\begin{array}{c}\text { Up slot time, } \\
\text { ms }\end{array}$ & $\begin{array}{c}\text { Welding } \\
\text { current, kA }\end{array}$ & $\begin{array}{c}\text { Welding } \\
\text { time, ms }\end{array}$ & $\begin{array}{c}\text { Pulse, } \\
-\end{array}$ & $\begin{array}{c}\text { Hold time, Electrode force, } \\
\text { ms }\end{array}$ \\
\hline 1-point & $0.8 / 1.5$ & 600 & 40 & 11 & 150 & 1 & 600 \\
10-point & $0.8 / 1.5$ & 600 & 20 & 10 & 160 & 1 & 600 & 200 \\
\hline
\end{tabular}

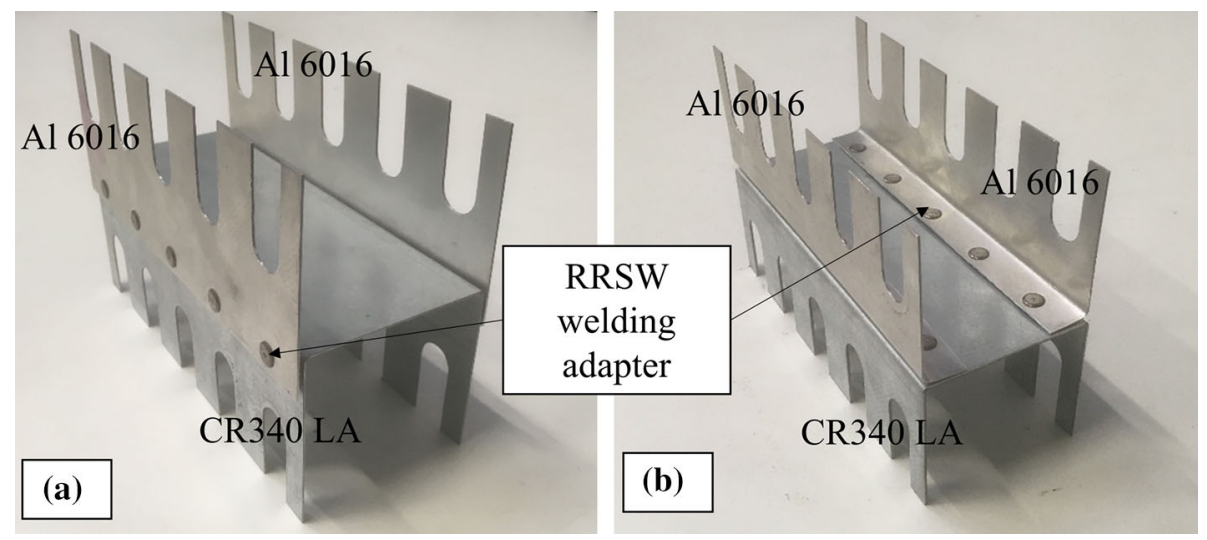

Fig. 5 (a) RRSW shear H-specimen with 10 joining elements and (b) RRSW peeling H-specimen

For the flat lap-shear specimen, standard clamping jaws were utilized. The free span length is defined as $160 \mathrm{~mm}$ according to DIN EN ISO 14324 (Ref 21). Compensator sheets were used in the clamping jaws to vertically align the two metal sheets with different sheet thicknesses. To properly clamp the H-specimen, a fixture was manufactured according to DIN EN ISO18592 (Figure 6c) (Ref 25).

A resonance pulsator works in the eigenfrequency range of the oscillation systems. Thus, the test frequency in the fatigue test must be determined by the resonance pulsator depending on the stiffness of the whole test system, which consists of the specimen and the test bench itself.
The fatigue tests on the 1-point lap-shear specimens were performed on the pneumatic test bench Dynamess TP 10 with a test frequency of $10 \mathrm{~Hz}$, as the 1-point SPR specimen showed a too low stiffness to be fatigue tested in the resonance test bench.

\section{Static Lap-Shear Tests and Evaluation}

Prior to the fatigue investigation, static lap-shear tests were carried out to analyze the failure behavior in quasi-static load cases, which can be compared to fatigue failure behavior. 


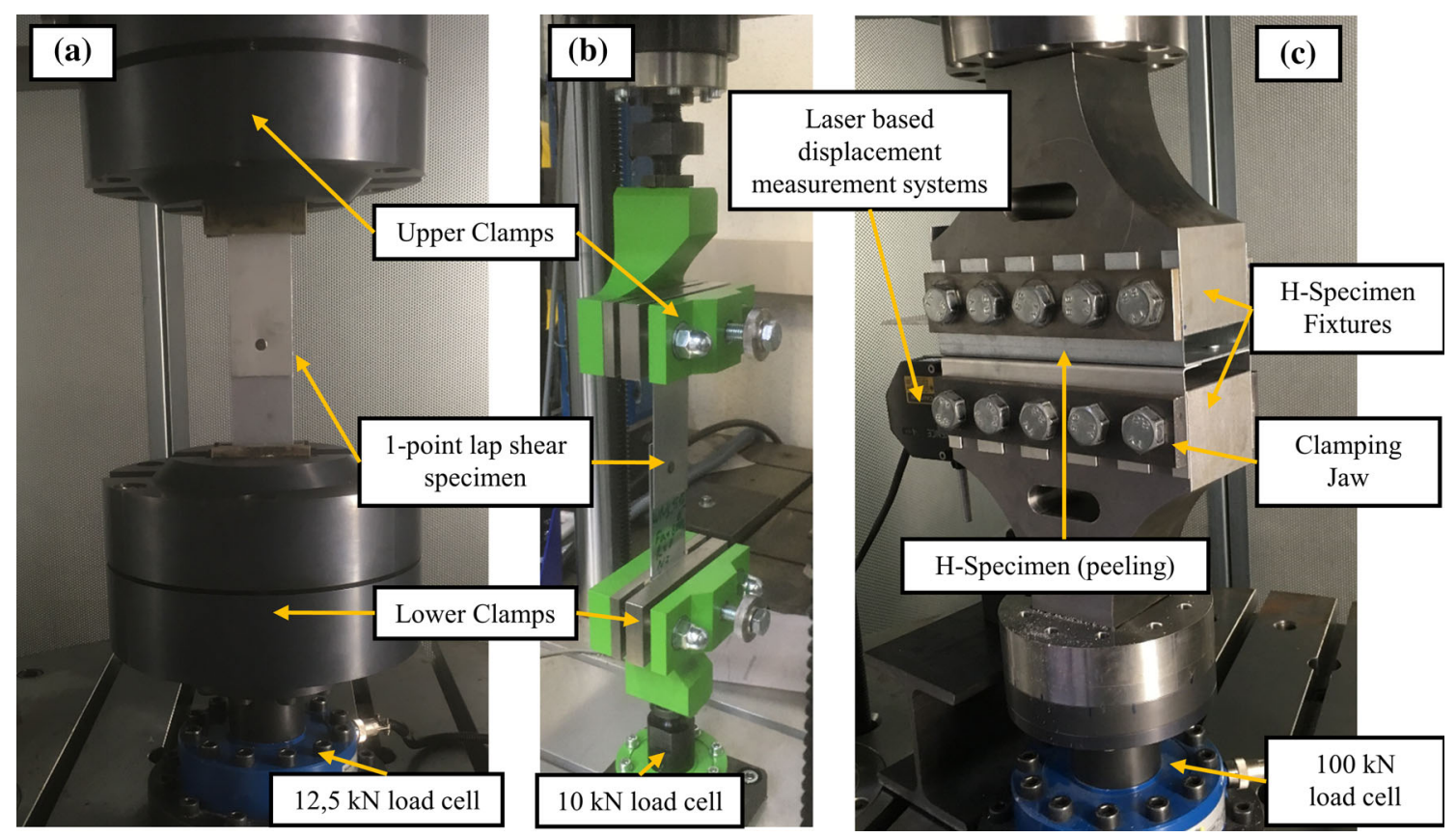

Fig. 6 Fatigue test setup for 1-point and 2-point shear specimens in (a) resonance test bench Sincotec PowerSwing $12.5 \mathrm{kN}$ for the thicker steel sheets, (b) pneumatic test bench Dynamess TP $10 \mathrm{kN}$ for the thinner steel sheets, and (c) test setup for the H-specimen in resonance test bench Sincotec PowerSwing $100 \mathrm{kN}$

Further, the initial load level for the SN-curves was determined with quasi-static tests. All quasi-static tests were conducted with the tensile test machine Z100 (ZwickRoell; Ulm, Germany). The cross head speed was set to $2 \mathrm{~mm} / \mathrm{min}$ to guarantee quasi-static loading conditions (Ref 29, 30), and the free span length was set to $160 \mathrm{~mm}$ (Ref 21). Compensator sheets were used in the clamping jaws to vertically align the two metal sheets with different sheet thicknesses. The compensator sheets for the RRSW specimen had to take the characteristic $1 \mathrm{~mm}$ gap between the steel and $\mathrm{Al}$ into account.

\subsection{Results of the 1-Point Lap-Shear Tests}

Figure 7 shows the force displacement curves of SPR and RRSW with the two different thickness combinations ( $\mathrm{C} 1$ with $0.8 \mathrm{~mm}$ steel and $1.0 \mathrm{~mm} \mathrm{Al}$; 2 with $1.5 \mathrm{~mm}$ steel and 1.0 $\mathrm{mm} \mathrm{Al)} \mathrm{according} \mathrm{to} \mathrm{the} \mathrm{test} \mathrm{matrix,} \mathrm{which} \mathrm{is} \mathrm{defined} \mathrm{in}$ Table 2. Due to the very good reproducibility of the static lapshear tests only 3 specimens per test were used. For SPR, the averaged maximum force for both thickness combinations was $\mathrm{F}_{\text {max }, \mathrm{HHSN}}=2.5 \mathrm{kN}$. For RRSW, the averaged maximum force for the thinner thickness combination (C1) was $\mathrm{F}_{\text {max }, \mathrm{RRSW}}=2.34 \mathrm{kN}$, and for the thicker thickness combination (C2) was about $\mathrm{F}_{\max , \mathrm{RRSW}}=2.1 \mathrm{kN}$.

The failure pattern of the SPR connection showed for the 0.8 $\mathrm{mm}$ steel thickness a failure in both the $\mathrm{Al}$ and steel. However, for the $1.5 \mathrm{~mm}$ steel thickness, failure occurred only in Al. The differences in failure for these two combinations are caused by the different bottom sheet thickness, which was lower for the $0.8 \mathrm{~mm}$ steel sheet (see Figure 3a-b), and the loading conditions. The thinner specimen $\mathrm{C} 1$ exhibited an overlapped shear-out and rivet pull-out failure due to the excessive bending of the specimen, due to its low stiffness. For the thicker specimen $\mathrm{C} 2$, the bending was smaller, resulting in a smaller overlapped pull-out force and a predominant shear failure.
Nevertheless, for both steel sheet thicknesses, SPR exhibited the same failure force level.

For RRSW, the failure patterns of both combinations $\mathrm{C} 1$ and $\mathrm{C} 2$ were also different. For C1 with the thinner steel sheet, the loading condition was not purely shear but also an overlap by a higher pull-out force, as stated above. The failure was a combination of shear and rivet pull-out. For C2 with the thicker steel sheet, the failure occurred predominantly by shear (Figure 8). The shear failure resulted in a lower maximum force in $\mathrm{C} 2$.

\subsection{Results of the 2-Point Lap-Shear Tests}

Figure 8 displays the results of the lap-shear test with a 2 point specimen under the same circumstances as the test for the 1-point specimen. A comparison of the test results of 1- and 2point specimens for the SPR test series revealed that the force level was simply doubled, indicating that the same load acted on each joining element. For RRSW, the force value was also doubled for C1 ( $0.8 \mathrm{~mm}$ steel). Its failure appearance of strong pull-out of the rivets was quite similar to the 1-point lap-shear test, as both specimen types experienced severe bending due to their low stiffness. However, for the $1.5 \mathrm{~mm}$ steel sheet thickness, the averaged maximum force of $F_{\text {max, } R R S W}=7.3 \mathrm{kN}$ was three times higher with regard to the RRSW 1-point specimen. The failure occurred mainly by shear. The higher lap-shear strength of the $1.5 \mathrm{~mm}$ specimen in comparison with the $0.8 \mathrm{~mm}$ specimen was due to the higher stiffness of the 1.5 $\mathrm{mm}$ specimen, which resulted in less bending overall.

The averaged maximum force of the $1.5 \mathrm{~mm}$ RRSW lapshear specimen exceeded the force level of the corresponding SPR 2-point specimen by more than $50 \%$. The joining strength of SPR was based only on form fit, which is mainly influenced by the rivet's interlocking width in the die-sided sheet. Similarly, for RRSW, the interlocking of the steel rivet in the Al contributed to the joint strength. Since the interlocking of 

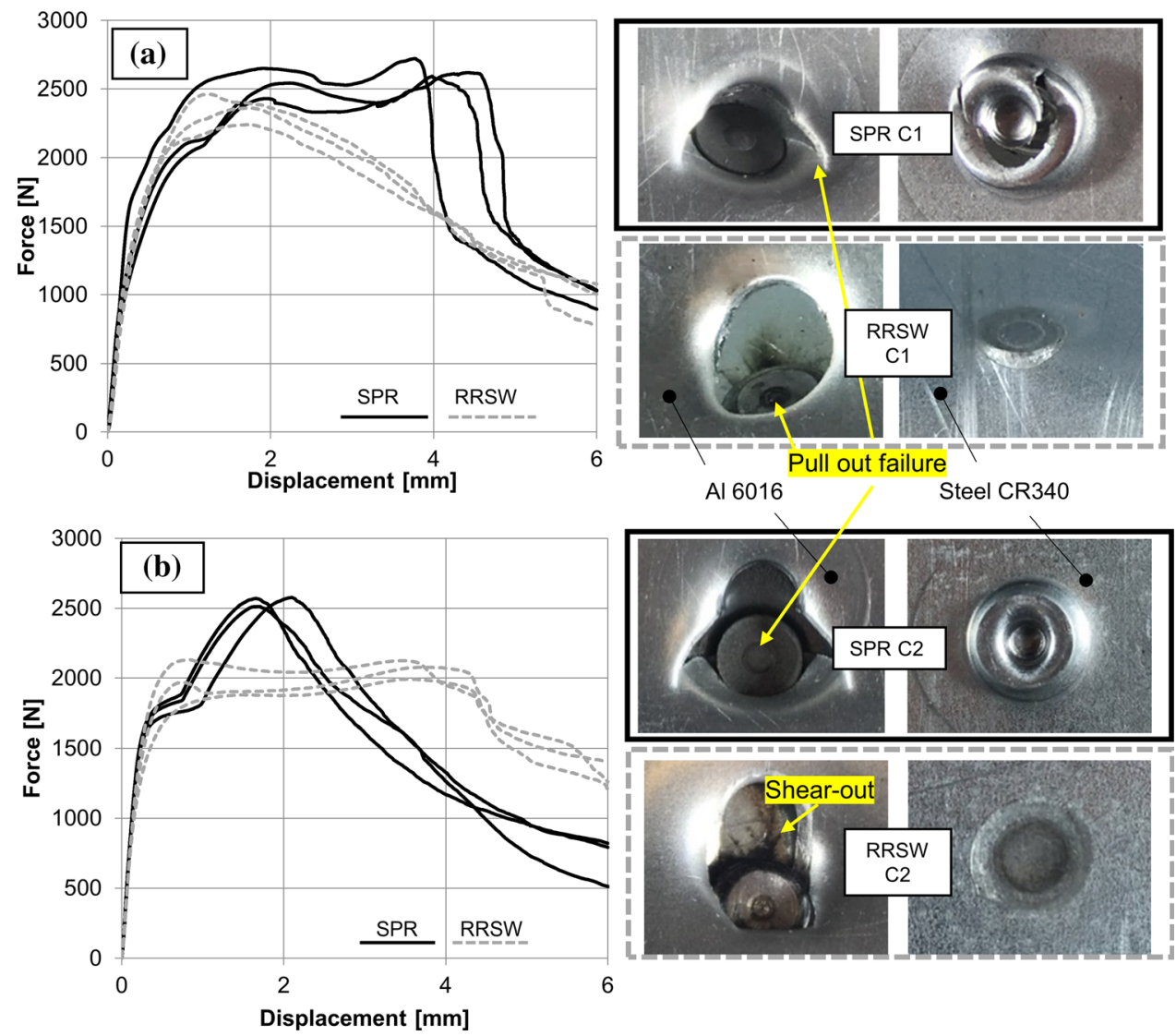

Fig. 7 Static Force-displacement curves of 1-point lap-shear test (a) material combination $\mathrm{C} 1$ and (b) $\mathrm{C} 2$; (pictures on the right depict the specimen from both sides)

the rivet in RRSW was generally larger than in SPR (see Fig. 3 in comparison with Fig. 1), a higher level of force could be reached with RRSW, as long as the Al strength was equal for both joining techniques.

Table 4 summarizes the maximum forces obtained in all static lap-shear tests. For all the RRSW static test series, it can be summarized that no failure was observed in the steel sheets.

\section{Fatigue Tests and Evaluation}

The fatigue test setup for 1-point, 2-point, and H-specimens is shown in Fig. 6. All tests were conducted force controlled with tension-tension load case $(\mathrm{R}=0)$. The fatigue behavior was investigated in the range of $10^{4}$ to $10^{7}$ load cycles.

\subsection{Results of the 1-Point Specimen Tests}

In Figure 9a, the SN-curves of the fatigue tests are plotted. For material combination $\mathrm{C} 1$ (1 $\mathrm{mm} \mathrm{Al}$ and $0.8 \mathrm{~mm}$ steel), the fatigue strength of RRSW was much smaller than that of SPR, although their static strengths were similar (see Table 4). For $\mathrm{C} 2$ (1 $\mathrm{mm} \mathrm{Al}$ and $1.5 \mathrm{~mm}$ steel), the two SN-curves showed nearly the same inclination $(\mathrm{k}=5$ for RRSW, $\mathrm{k}=4.9$ for SPR). In comparison with the SPR specimen, the SN-curve of the RRSW specimen was horizontally shifted to the right, indicating that the force amplitude at $10^{6}$ load cycles was $\sim 10 \%$ higher.
The failure pattern of the RRSW specimen with thickness combination $\mathrm{C} 1$ (Figure 9b) exhibited cracks in the $0.8 \mathrm{~mm}$ CR340 steel sheet around the welding nugget. During the fatigue test, it was observed that the first crack always occurred in the $0.8 \mathrm{~mm}$ steel sheet around the welding nugget. The initial failure in the $0.8 \mathrm{~mm}$ steel sheet was followed by a failure in the $\mathrm{Al}$ sheet, which finally led to the breakage of the whole specimen. This is a major difference in comparison with the static loading condition, where no failure in the steel sheet around the spot weld could be observed. In contrast to $\mathrm{C} 1$, in the $\mathrm{C} 2$ specimens, no failure in the steel could be observed.

The SPR specimens showed no failure on the steel sheet side. The fracture of the SPR specimen started in the Al sheet as a sickle shape ("eyebrow failure") over the rivet and propagates after a few cycles through the whole Al sheet crosssection, which led to specimen breakage. The failure pattern was clearly different from that of the static loading conditions, where the specimen initially exhibited a shear-out failure and finally a rivet pull-out due to the bending of the specimen.

The failure mode of the RRSW specimen in thickness combination $\mathrm{C} 2$ was similar to both the $0.8 \mathrm{~mm}$ and $1.5 \mathrm{~mm}$ SPR specimens, suggesting that failure occurred only in the $1.0 \mathrm{~mm}$ thick $\mathrm{Al}$ sheet.

\subsection{Results of the 2-Point Specimen Tests}

All 2-point specimen tests were conducted in the same way as the 1-point tests shown in Fig. 6(a). The SN-curves of the tests are shown in Figure 10. The scatter of the fatigue tests with the 2-point specimen was lower for both SPR and RRSW 

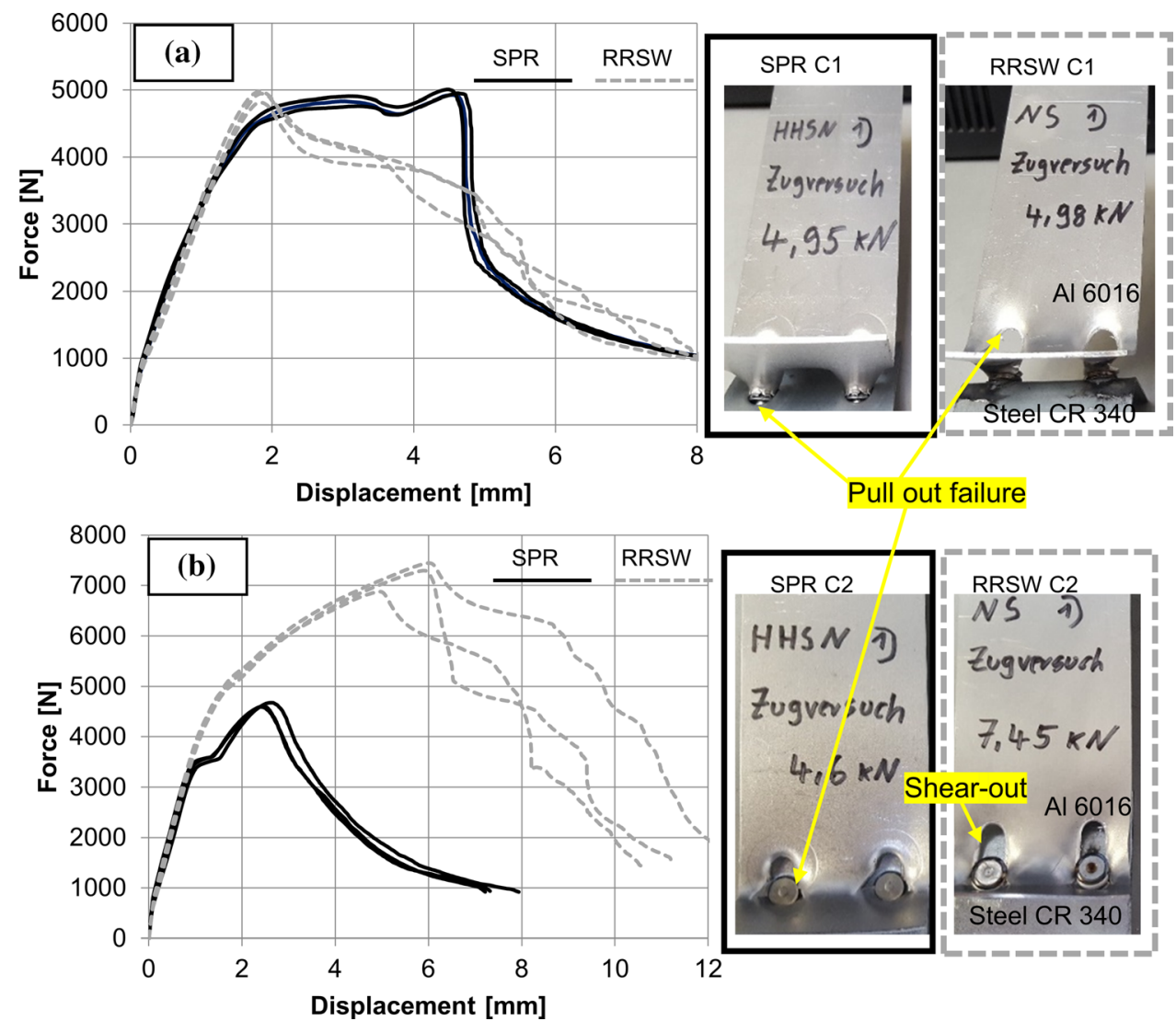

Fig. 8 Static Force-displacement curves of 2-point lap-shear test (a) material combination $\mathrm{C} 1$ and (b) C2; (pictures on the right depict the specimen from both sides)

Table 4 Maximum static lap-shear strength of 1-point and 2-point SPR and RRSW specimen

\begin{tabular}{lccc}
\hline Max. static lap-shear strength, $\mathbf{k N}$ & 1-point specimen & 2-point specimen & Material combination \\
\hline Self-piercing riveting (SPR) & 2.56 & 5.00 & $\mathrm{C} 1$ \\
& 2.50 & 4.67 & $\mathrm{C} 2$ \\
Resistance rivet spot welding (RRSW) & 2.34 & 4.98 & $\mathrm{C} 1$ \\
& 2.10 & 7.44 & $\mathrm{C} 2$ \\
\hline
\end{tabular}

in comparison with the 1-point test series. This phenomenon can be explained as follows: In a 2-point specimen, due to the load redistribution effect, small errors in specimen manufacturing do not necessarily result in specimen breakage.

With a force amplitude of $\mathrm{F}_{\mathrm{a}}=564 \mathrm{~N}$ at $10^{6}$ cycles and $\mathrm{k}=$ 4.9 , the finite life fatigue strength of the $0.8 \mathrm{~mm}$ steel joined with RRSW was $35 \%$ lower than that of SPR, which exhibited a load amplitude of $\mathrm{F}_{\mathrm{a}}=885 \mathrm{~N}$ at $10^{6}$ cycles and $\mathrm{k}=4.12$. At $\mathrm{F}_{\mathrm{a}}=0.5 \mathrm{kN}$, the SPR specimen $(\mathrm{k}=5.5)$ reached the fatigue limit of $10^{7}$ load cycles, whereas the corresponding fatigue life for RRSW was $6 \bullet 10^{6}$ load cycles.

The C2 RRSW specimen exceeded the fatigue strength of the SPR specimens at the highest load amplitude level $\left(\mathrm{F}_{\mathrm{a}}=1.5 \mathrm{kN}\right)$, similar to the static tests (Figure $8 \mathrm{~b}$ ). However, with decreasing load amplitudes and increasing load cycles, the SPR specimen showed a higher durability. The SN-curve inclination of the SPR specimen $(\mathrm{k}=4.12)$ for the thickness combination $\mathrm{C} 2$ was similar to RRSW $(\mathrm{k}=4.2)$. The difference is that the SN-curve of SPR was shifted to the right side of the diagram. Therefore, the fatigue life of SPR at $10^{6}$ load cycles was $11 \%$ higher than that of RRSW.

As observed in Fig. 11, the fracture patterns of the 2-point specimens are similar to that of the 1-point specimen. For the $0.8 \mathrm{~mm}$ steel thickness, the SPR specimen failure was observed only in the Al sheet (Figure 11a), whereas for the RRSW specimen, failure starts in the steel around the welding nugget and propagates in a lateral direction through the steel sheet (Figure 11b). The higher the load amplitudes, the more failure observed in the $\mathrm{Al}$, similar to the failure pattern of the static tests displayed in Figure 8. At the lowest load amplitude in the $\mathrm{SN}$-diagram, which was $\mathrm{F}_{\mathrm{a}}=500 \mathrm{~N}$, no failure in $\mathrm{Al}$ was observed, although failure was seen in the steel part (Figure $11 \mathrm{~b})$.

For the 2-point specimen test series with the thicker $1.5 \mathrm{~mm}$ steel sheet, Figure 11c and d shows the fracture pattern for the SPR and RRSW specimens, respectively. With both joining 

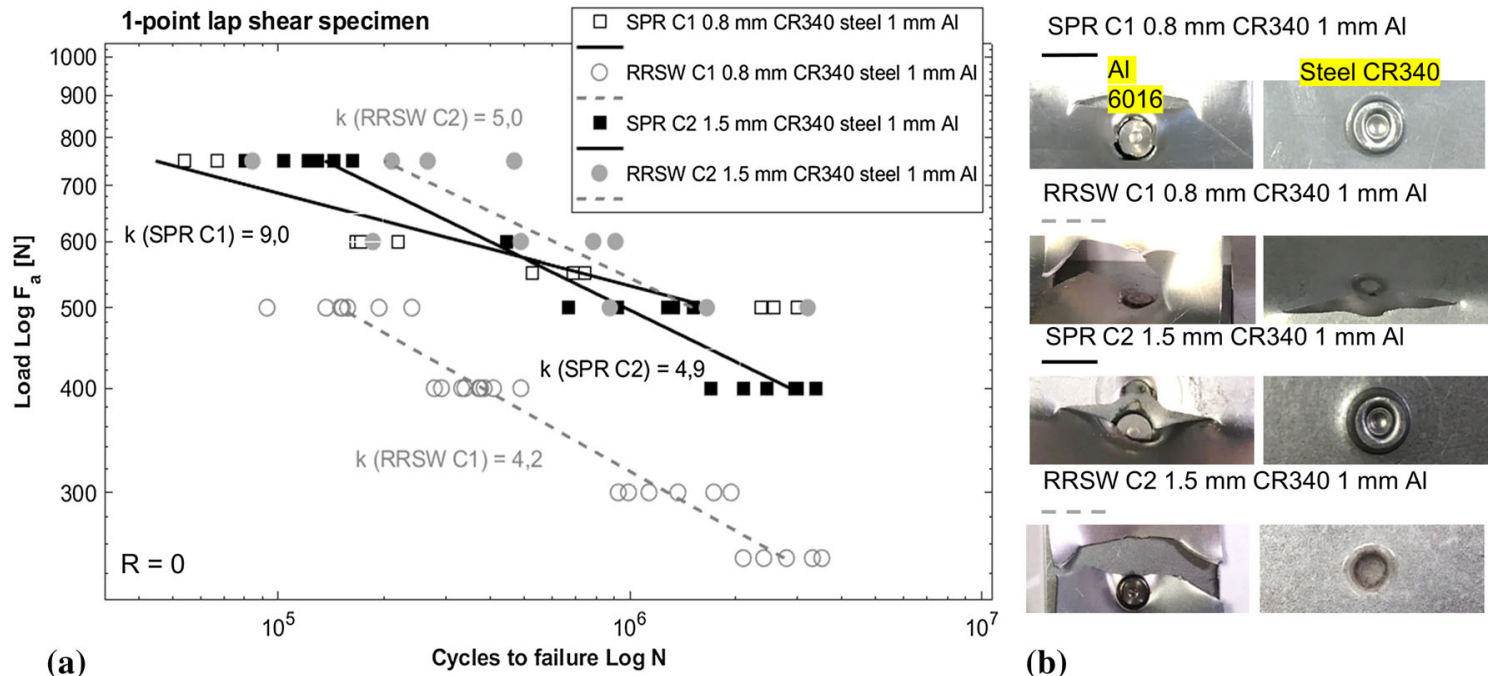

(a)

Cycles to failure $\log N$

(b)

Fig. 9 (a) 1-point specimen fatigue test of self-piercing riveting (SPR; solid line) and rivet resistance spot welding (RRSW; dashed line) SNcurves for material combination $\mathrm{C} 1$ and $\mathrm{C} 2$ (b) the fore- and backside of a SPR and RRSW fatigue-tested specimen

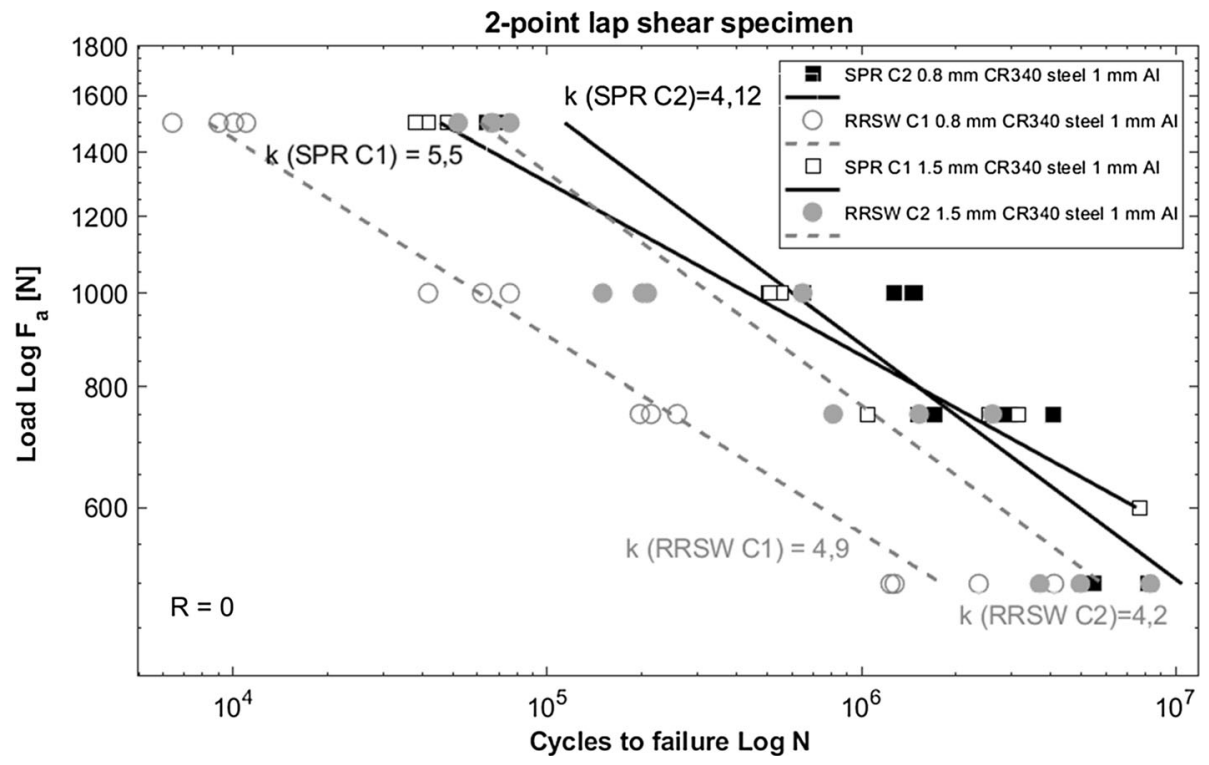

Fig. 10 2-point specimen fatigue test of self-piercing riveting (SPR; solid line) and rivet resistance spot welding (RRSW; dashed line) SNcurves for material combination $\mathrm{C} 1$ and $\mathrm{C} 2$

techniques, a sickle-shaped failure profile was observed in the $\mathrm{Al}$ sheet. For the RRSW specimen, the failure of the Al was not located in the heat-affected zone of the spot welds.

\subsection{Results of the H-Specimen Tests}

The H-specimens were tested using the fixture shown in Figure 6c. Since the H-specimen consisted of 10 joining points, the abort criterion of the fatigue test can be more complex and is not necessarily defined as specimen breakage, as with the 1- and 2-point specimens. An H-specimen can still transfer load even if the specimen exhibits visible cracks. Nevertheless, for the shear $\mathrm{H}$-specimen, specimen breakage was a suitable abort criterion, whereas for peeling $\mathrm{H}$ specimen, a stiffness-based abort criterion was found to be more suitable. This will be discussed in detail at the beginning of section 4.3.2.

4.3.1 Shear H-Specimen. The test frequency ranged between 83 and $95 \mathrm{~Hz}$ for the SPR and RRSW fatigue tests series. The high stiffness of the H-specimen led to higher eigenfrequencies of the vibration system. The SN-diagram of the fatigue test using the shear $\mathrm{H}$-specimen is shown in Figure 12.

The load level at $10^{6}$ cycles of the SPR shear H-specimen with the thinner steel $\mathrm{C} 1$ is $\mathrm{F}_{\mathrm{a}}=5.5 \mathrm{kN}$, which was $\sim 40 \%$ higher than the force level of the corresponding RRSW shear $\mathrm{H}$-specimen $\left(\mathrm{F}_{\mathrm{a}}=3.2 \mathrm{kN}\right)$. Due to the low inclination of the SPR H-specimen SN-curve with $\mathrm{k}=8.71$ in comparison with $\mathrm{k}=4.53$ of RRSW, the durability of the SPR was higher, especially at lower load levels and higher cycles to failure. The 
C1: $0.8 \mathrm{~mm}$ steel

C2: $1.5 \mathrm{~mm}$ steel
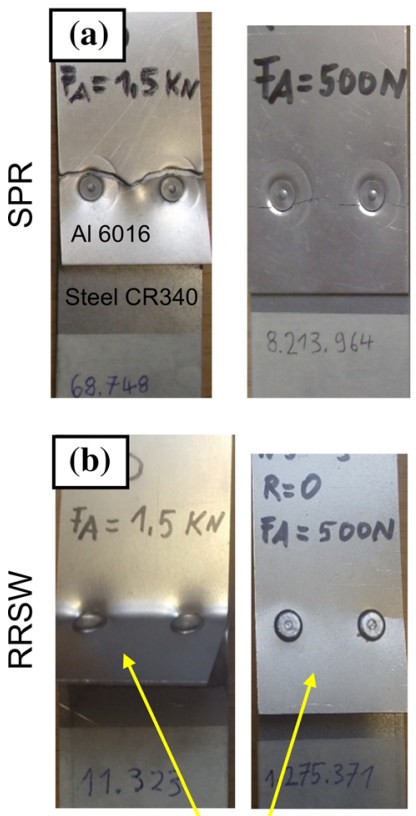

Excessive bending $\rightarrow$ low durability (c)
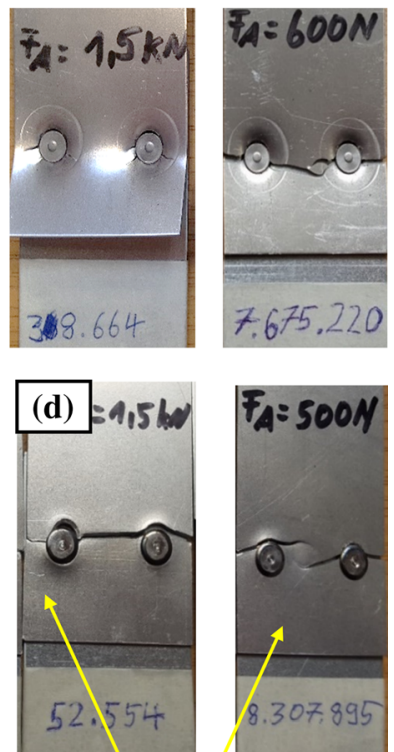

Less bending

$\rightarrow$ higher durability

Fig. 11 Comparison of the fatigue load-induced fracture pattern of 2-point lap-shear specimen on four load levels for (a) SPR material combination C1, (b) RRSW C1, (c) SPR C2 and (d) RRSW C2

SN-curve characteristics fitted well with the 1- and 2-point specimen, where SPR was also more durable at higher load cycles for material combination $\mathrm{C} 1$.

Also, for the thicker steel C2, the fatigue test results of the $\mathrm{H}$-specimen reflect the results obtained with the flat lap-shear specimen. In contrast to the 1-point specimen tests, the highest fatigue strength was achieved with RRSW. The force level at $10^{6}$ load cycles of the $\mathrm{SN}$-curve was $\mathrm{F}_{\mathrm{a}}=6.07 \mathrm{kN}$, which was $15 \%$ higher than the force level of the corresponding SPR specimen $\left(\mathrm{F}_{\mathrm{a}}=5.1 \mathrm{kN}\right)$. The $\mathrm{SN}$-curves slopes of SPR and RRSW for material combination $\mathrm{C} 2$ were similar $(\mathrm{k}=6.45$ for RRSW and $\mathrm{k}=6.89$ for SPR). However, the SN-curve inclination of $\mathrm{k}=6.45$ for RRSW was higher than in the previous test series using 1- and 2-point specimens. These findings suggest that due to stress redistribution, small singular cracks can be compensated by undamaged joining points.

Similar to the previous tests with 1- and 2-point specimens, only the combination of the thin steel sheet and RRSW as the joining technique exhibited failure in the steel, whereas the other three test series showed failure in the Al sheet only (Figure 12b).

4.3.2 Peeling H-Specimen. The test frequency ranged between $34-38 \mathrm{~Hz}$ for the SPR and RRSW peeling $\mathrm{H}$-specimen fatigue. The low stiffness of the peeling $\mathrm{H}$-specimen led to low eigenfrequencies of the vibration system.

For the shear $\mathrm{H}$-specimen, where no base material failure occurred and the stiffness remained nearly constant until rupture, specimen breakage was used as the abort criterion of
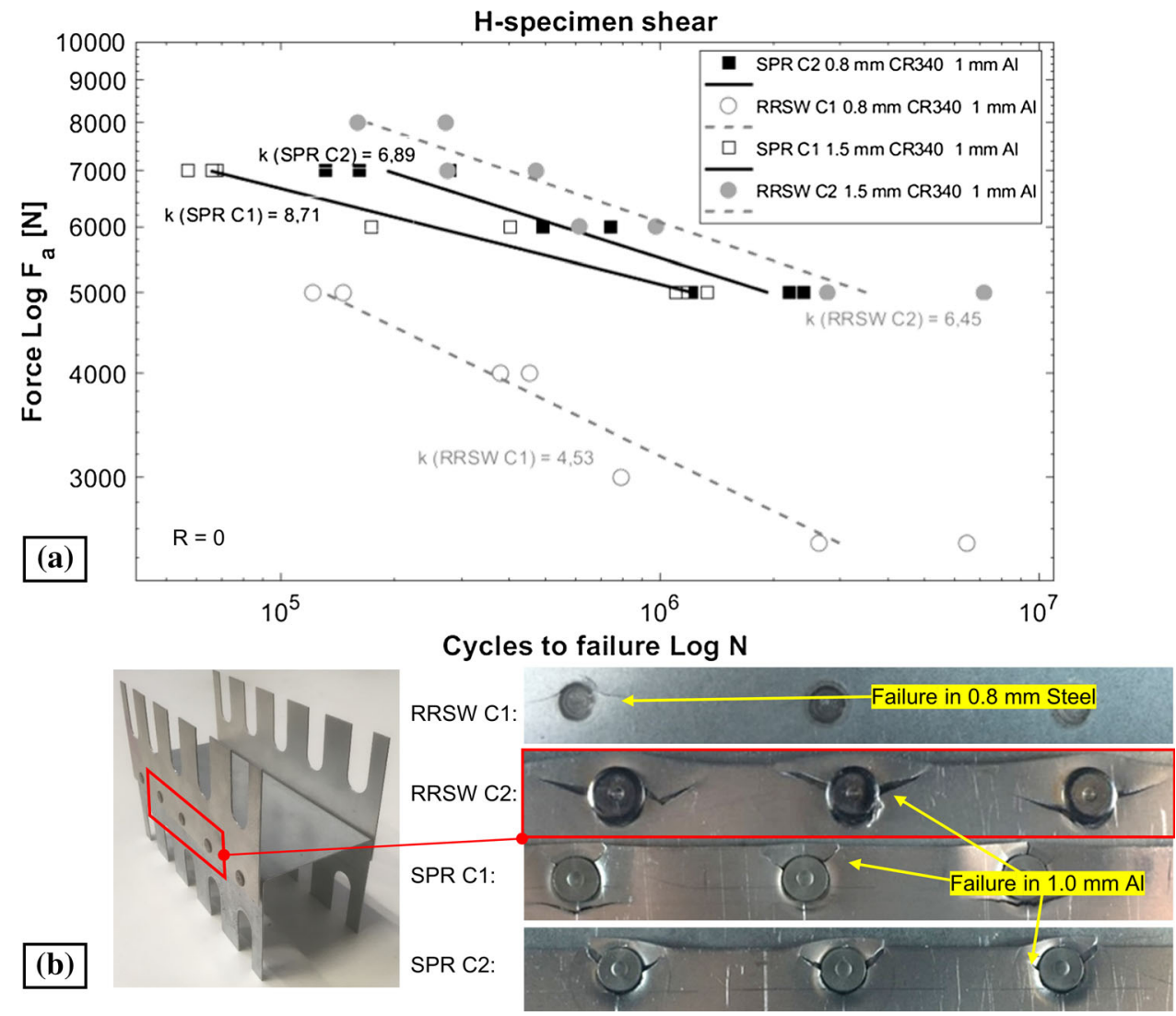

Fig. 12 (a) Fatigue test of SPR- and RRSW-H-Specimen (Shear) with material combinations C1 and C2 (b) the location of failure in the SPR and RRSW specimen 
the fatigue test. By contrast, due to the sharp fillet radius of the $\mathrm{Al}$ profiles, failure occurred in the Al base material for both material combinations [see Fig. 14(b)]. This Al base material failure in combination with failure around the joining element led to a smooth but constant drop in stiffness of the peeling $\mathrm{H}$ specimen. Figure 13 shows representative stiffness profiles of a peeling H-specimens at a load amplitude of $750 \mathrm{~N}$. After a relatively short phase, where the specimens typically showed a $5-10 \%$ rise in stiffness due to setting and void-filling effects around the joining element, the specimen stiffness decreases. To take the base material failure into account for the peeling $\mathrm{H}$ specimen, $40 \%$ stiffness loss was considered to be the abort criterion. Thus, the SN-curves of the fatigue tests in Fig. 14(a) were determined using $40 \%$ loss of stiffness as the abort criterion.

For C1, the SN-curves of the SPR specimens showed a slope of $\mathrm{k}=5.0$ and $\mathrm{k}=3.8$ for RRSW. The fatigue force level at $10^{6}$ load cycles of the SPR test series with this combination equals $\mathrm{F}_{\mathrm{a}}=610 \mathrm{~N}$, indicating a $15 \%$ higher force level than the corresponding RRSW. This result is in good agreement with the fatigue tests of the shear $\mathrm{H}$-specimen fatigue test results.

For the material combination $\mathrm{C} 2$, the $\mathrm{SN}$-curves of both SPR and RRSW peeling H-specimens nearly overlay. Both exhibited a force level at $10^{6}$ load cycles of $F_{a}=680 \mathrm{~N}$ and $\mathrm{k}=5$. Comparable to the shear test, the RRSW peeling specimens showed fatigue cracks in the $0.8 \mathrm{~mm}$ steel around the welding nugget, which limited the durability of the connection.

For the RRSW peeling specimen, beside the cracks in the $\mathrm{Al}$ sheet around the welding point, additional failures were observed in the Al base material, as shown in Fig. 14(b). By contrast, in the SPR peeling H-specimen fatigue tests, the cracks started directly from the rivet, indicating that peeling stress singularities were higher. This effect can be explained by the higher amount of interlocking, which can be observed in the micro-section of RRSW (Figure 1c) in comparison with SPR (Figure 3).

\section{Discussion}

Since RRSW is a hybrid joining technique consisting of riveting and welding, its fatigue properties are expected to be similar to those of spot-welded joints. Several previous studies have already shown that mechanical joining techniques exhibit better fatigue behavior in comparison with welding (Ref 13, 14, $17,-20)$ as described in section 1 . The welding heat leads to a local hardening around the weld nugget, which creates a metallurgical notch. Notches reduce the durability of a structure, which normally leads to a lower fatigue limit of spot-welded structures in comparison with mechanical joints, such as SPR.

Figure 15 shows the summary of test results on all four specimens in section 4 . For the material combination $\mathrm{C} 1$ with a thinner steel sheet (Figure 15a and b), both the k-values and fatigue strength of SPR were better than the RRSW. The phenomenon discovered previously (see section 1) for Al-Al or steel-steel joining using SPR and RSW that SPR shows always larger k-value in comparison with RSW can also be confirmed for RRSW. For C2 with a thicker steel sheet, although the kvalues were better for SPR, the fatigue strengths of the $\mathrm{H}$ specimens for RRSW were better or equal to SPR. For the 1- or 2-point specimens, SPR was always better than RRSW. However, since the H-specimens represent the real vehicle component behaviors much better than the 1- or 2-point specimens, the results of $\mathrm{H}$-specimens should be used to evaluate the performance of the joining technique for real structure in body-in-white.

The different sheet metal thickness dependency of the relative fatigue strength of RRSW and SPR can be explained by the geometrical and metallurgical effects.

\subsection{Geometrical Effects on RRSW Durability}

For $\mathrm{C} 1$ with thin $0.8 \mathrm{~mm}$ steel sheets thickness, the fatigue strength of all RRSW specimens was significantly lower in comparison with the SPR specimens, as described by forces

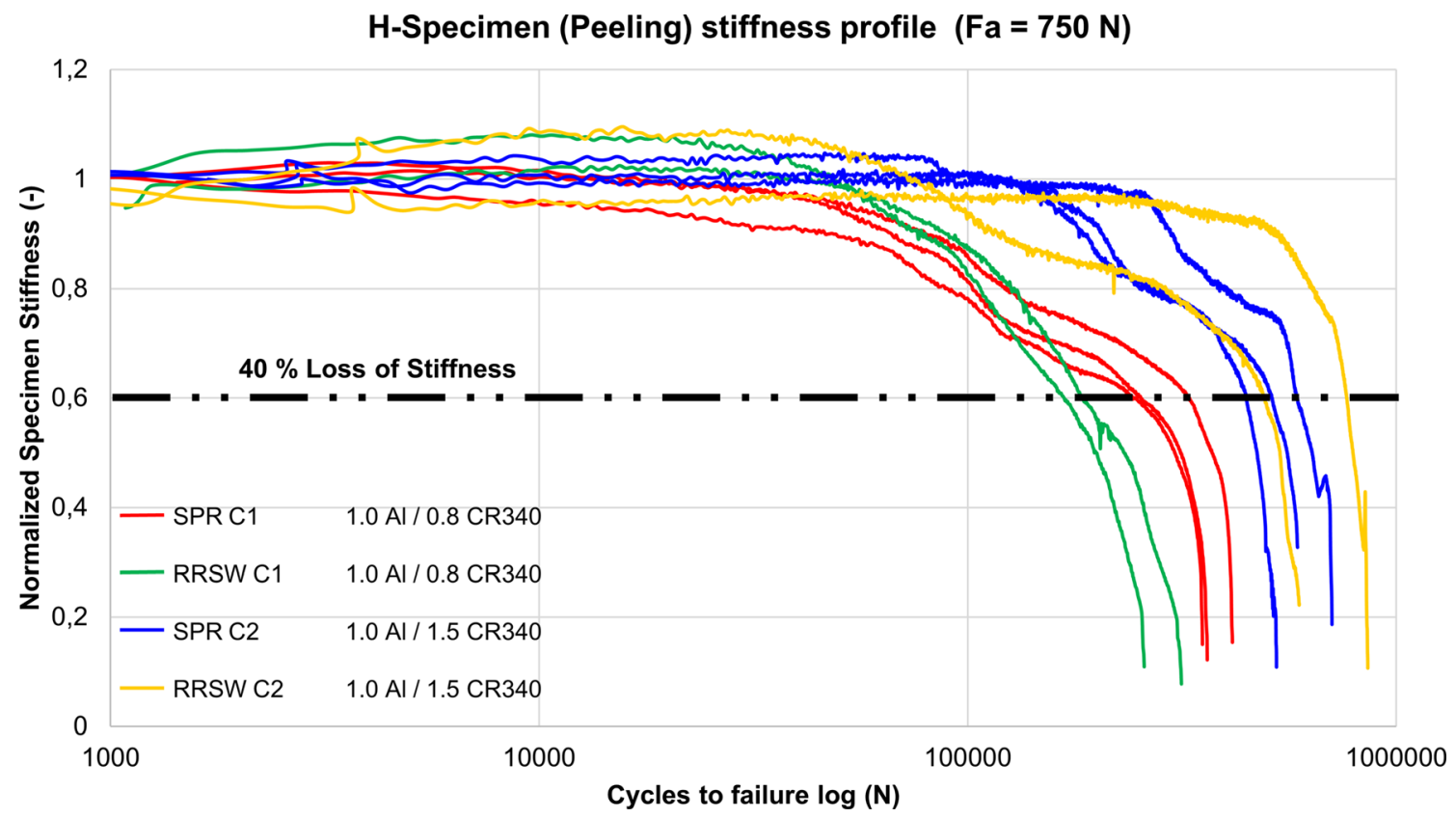

Fig. 13 Stiffness profiles of H-Specimen (peeling) of fatigue tests at load level $750 \mathrm{~N}$ 


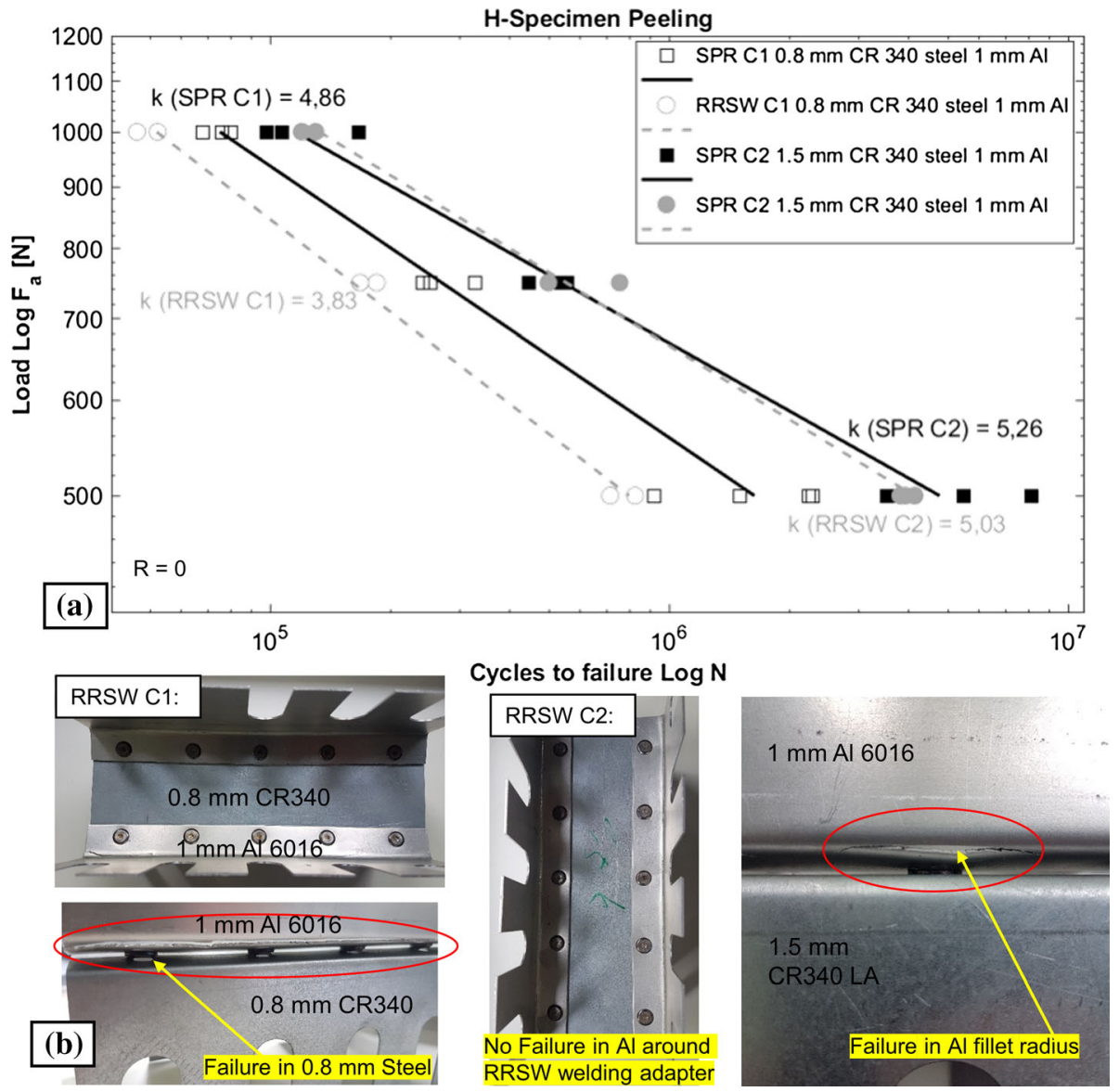

Fig. 14 (a) Fatigue test of SPR- and RRSW-H-Specimen (Peeling) with material combinations C1 and C2 (b) fracture in H-Specimen fillet radius of the RRSW specimen

that acted on the joint of the RRSW shear specimen (Figure 16) (Ref 31). Due to the gap (S), which is based on the RRSW concept (see also Fig. 1), the tension forces $F_{s t}$ cause a bending moment around the center of the joining element, according to Eq. 1:

$M_{\mathrm{b}}=F \cdot\left(0.5 T_{S t}+S+0.5 T_{A l}\right)$.

Thus, the shear stress caused by $F$ is superimposed with a tensile force induced by the bending moment $M_{b}$, which is in Figure 16 referred to as bending stress $\sigma_{Z 2}$ (Eq 2), which maximum value is approximately given by $\mathrm{Eq} 4$, if the difference between the sheet metal thickness of $\mathrm{Al}$ and steel is small:

$\sigma_{z}=\frac{M_{\mathrm{b}}}{I_{y}} * z$

with

$I_{y}=\int z d A$

$$
\begin{aligned}
\sigma_{Z 2, \max }\left(z=0.5 S+T_{\mathrm{st}}\right) & \approx \frac{M_{b} \cdot\left(0.5 S+T_{\mathrm{st}}\right)}{I_{\mathrm{b}}} \\
& \approx \frac{M_{\mathrm{b}}}{b \cdot T_{\mathrm{St}} \cdot\left(0.5 S+T_{\mathrm{St}}\right)}
\end{aligned}
$$

$I$ : bending inertia, $b$ : width of the lap-shear specimen.

If the gap is zero, $\sigma_{Z 2, \max }=M_{b} /\left(b \cdot T_{S t}^{2}\right)$.
Based on Eq 4, it is obvious that the bending stress is higher for RRSW specimens in comparison with SPR specimens, which have no gap between the two sheet metals. However, bending stress is reduced if the steel thickness $T_{s t}$ increases. For a lap shear specimen $\mathrm{C} 2$ (1.5 mm steel, $1.0 \mathrm{~mm} \mathrm{Al})$ under a tensile force $F$ of $1 \mathrm{kN}$ and a $1 \mathrm{~mm}$ gap a bending stress is calculated to $\sigma_{Z 2 \max } \approx 15 \mathrm{MPa}$, whereas for $0.8 \mathrm{~mm}$ steel thickness its value is $36.5 \mathrm{MPa}$. For SPR under same load condition but with no gap, bending stress component can be approximated to $\sigma_{Z 2 \max } \approx 8.3 \mathrm{MPa}$ for $\mathrm{C} 2$, respectively 28 $\mathrm{MPa}$ for $\mathrm{C} 1$. The gap works like a notch. Hence, the crack forms in the steel sheet if the steel thickness is low and no crack forms if the steel is thicker. For the same reason, the fatigue strength of RRSW specimens with thinner steel sheets is lower compared to SPR. For a thicker steel sheet, the bending stress increase is limited, so that the fatigue life of RRSW is comparable or even better than SPR. For the quasi-static tests, the bending stress is small in comparison with the static stress. In these cases, the strength of RRSW is equal to or better than SPR even for small steel thicknesses.

\subsection{Metallurgical Effects}

The steel rivet, which is used as a welding adapter in the RRSW process, exhibited a thickness of $3 \mathrm{~mm}$. To weld this thick rivet together with a thin steel sheet, the weld current must be limited to avoid metal expulsion. Therefore, the nugget size was also limited. To increase the nugget size to meet 


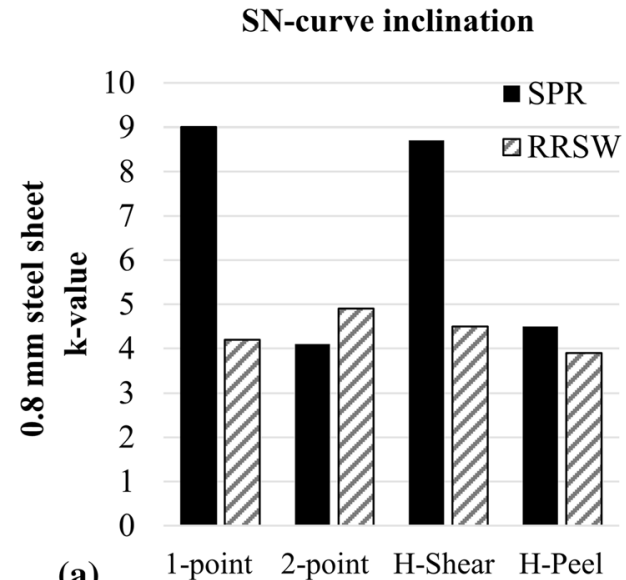

(a)

1-point 2-point H-Shear H-Peel

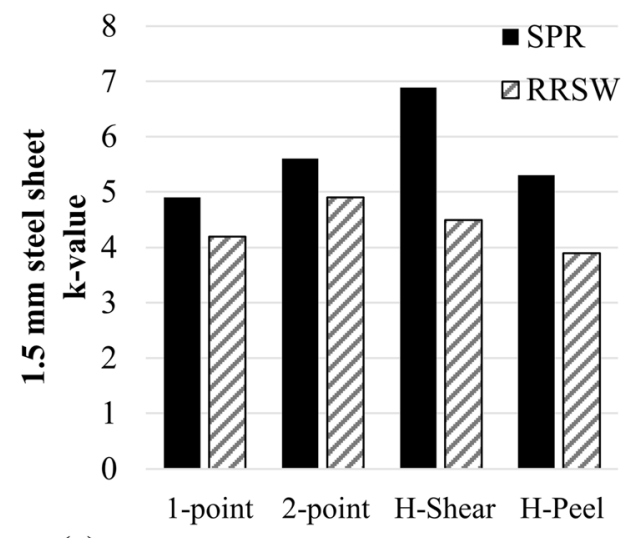

(c)
Rel. fatigue force at $10^{6}$ cycles

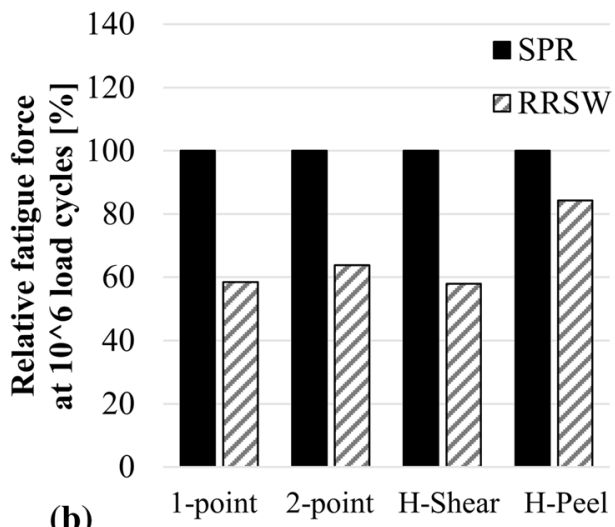

(b)

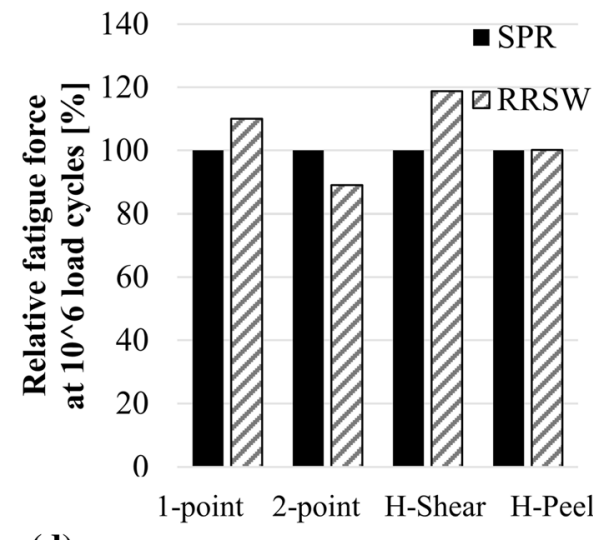

(d)

Fig. 15 Summarizing comparison of the SN-curve inclinations and relative fatigue forces at $10^{6}$ load cycles for the self-piercing riveting (SPR) and rivet resistance spot welding (RRSW) fatigue test for $\mathrm{C} 1(1.0 \mathrm{~mm} \mathrm{Al} 6016$ sheet joined to a thin $0.8 \mathrm{~mm}$ steel sheet (a), (b) and for $\mathrm{C} 2$ $(1.0 \mathrm{~mm} \mathrm{Al} 6016$ sheet joined to a thick $1.5 \mathrm{~mm}$ steel sheet (c), (d)

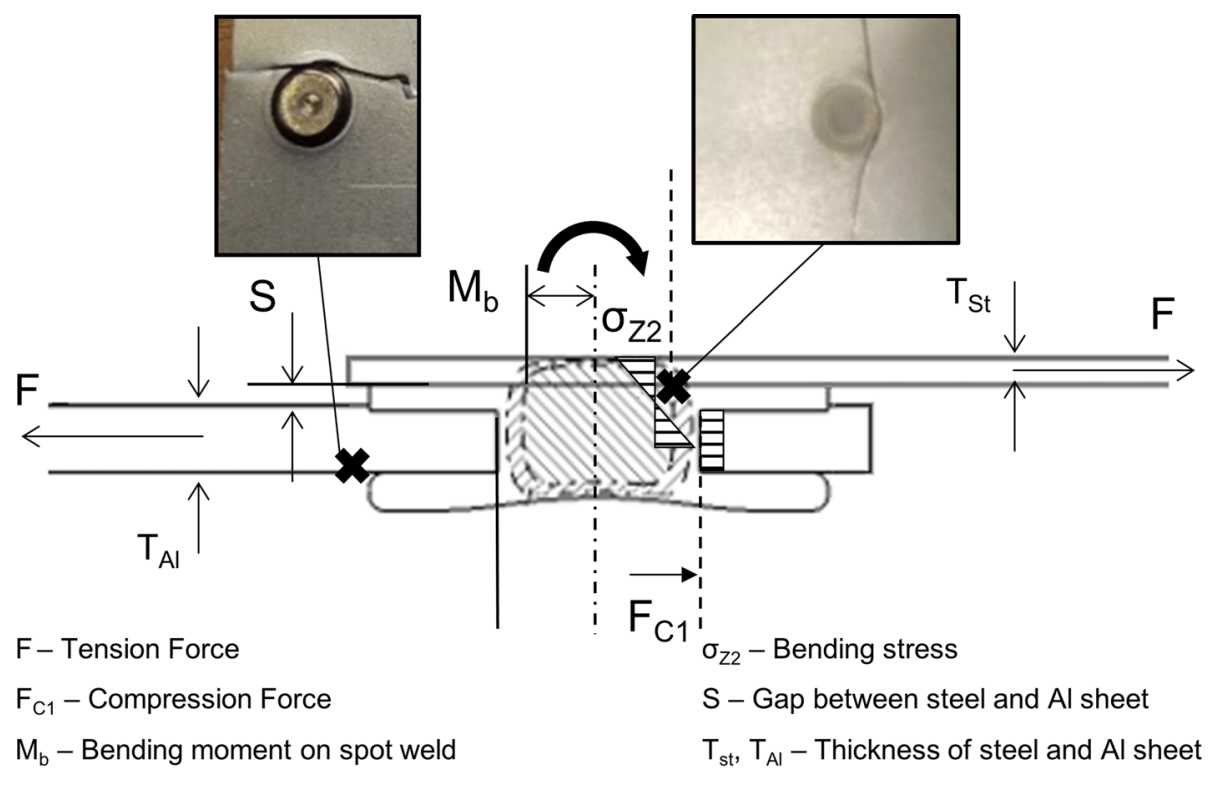

Critical Areas of the RRSW Joint

Fig. 16 Forces acting on the rivet resistance spot welding (RRSW) lap-shear specimen: tension force in the specimen longitudinal direction causes a bending moment $\left(\mathrm{M}_{\mathrm{b}}\right)$ on the joint due to the gap (S) [31] 
specifications, in this work, a relatively large current was chosen for the $0.8 \mathrm{~mm}$ steel thickness, which might result in partial Al-melting in the Al sheet metal.

To investigate the influence of the welding heat on the $\mathrm{Al}$ and steel microstructure, a micro-hardness test according to Vickers with HV0.2 for Al and HV0.3 for steel was conducted. The micro-hardness measurement results are shown in Fig. 17(a) for the $0.8 \mathrm{~mm}$ steel sheet thickness (C1) and in Fig. 17(b) for the $1.5 \mathrm{~mm}$ steel sheet thickness (C2). Since both micro-sections were cut from a fatigue-tested shear H-specimen, voids could be found between the rivet and the metal sheets on the right side of the cross section. The micro-sections also revealed that the spot weld was not in perfect vertical alignment with the borehole in the center of the Al sheet, indicating that the micro-hardness was not symmetrically distributed over the whole cross section. Consequently, the hardening effect in both sheet metals and rivet base material was more distinct on the left side of the cross section.

A comparison of the hardness around the spot weld with the raw material hardness showed an overall increase in the hardness of the rivet base material and the steel sheet. An approximately $20 \%$ loss of hardness (from 82 HV to $62 \mathrm{HV}$ ) in the heat-affected zone of the $\mathrm{Al}$ sheet in the $\mathrm{C} 1$ combination was found, whereas for the thicker $\mathrm{C} 2$ combination, the hardness reduction of $\mathrm{Al}$ sheet was very small ( $\mathrm{HV}$ changes from 82 to 78 ). For $\mathrm{C} 1$, it was difficult to determine if the $\mathrm{Al}$ sheet was partially melted during welding. For C2, this was eventually excluded. Since the fatigue cracks in Al sheet metal touched the weld spot, it could have been caused by the hardness reductions around the weld spot.

Considering the hardness changes in the steel sheet, Figure 17 shows a distinct drop in hardness in both steel sheet thicknesses $\mathrm{C} 1$ and $\mathrm{C} 2$. For $\mathrm{C} 1$, it dropped from $375 \mathrm{HV}$ to $195 \mathrm{HV}$ and for C2, from $389 \mathrm{HV}$ to $187 \mathrm{HV}$. This strong hardness drop created a metallurgic notch in the steel sheet. Fatigue failure will originate from the metallurgic notch if the stress is high enough. This was the case for the thinner steel C1, as discussed above in 5.1.

However, even if fatigue failure could be observed in the thinner steel sheets, the micro-sections and the characteristic eyebrow failure pattern over the HAZ were comparable to resistance spot welding of steel to steel sheets (Ref 18, 32). Interfacial failure of the spot weld was avoided, indicating that welding parameters were adequately obtained.
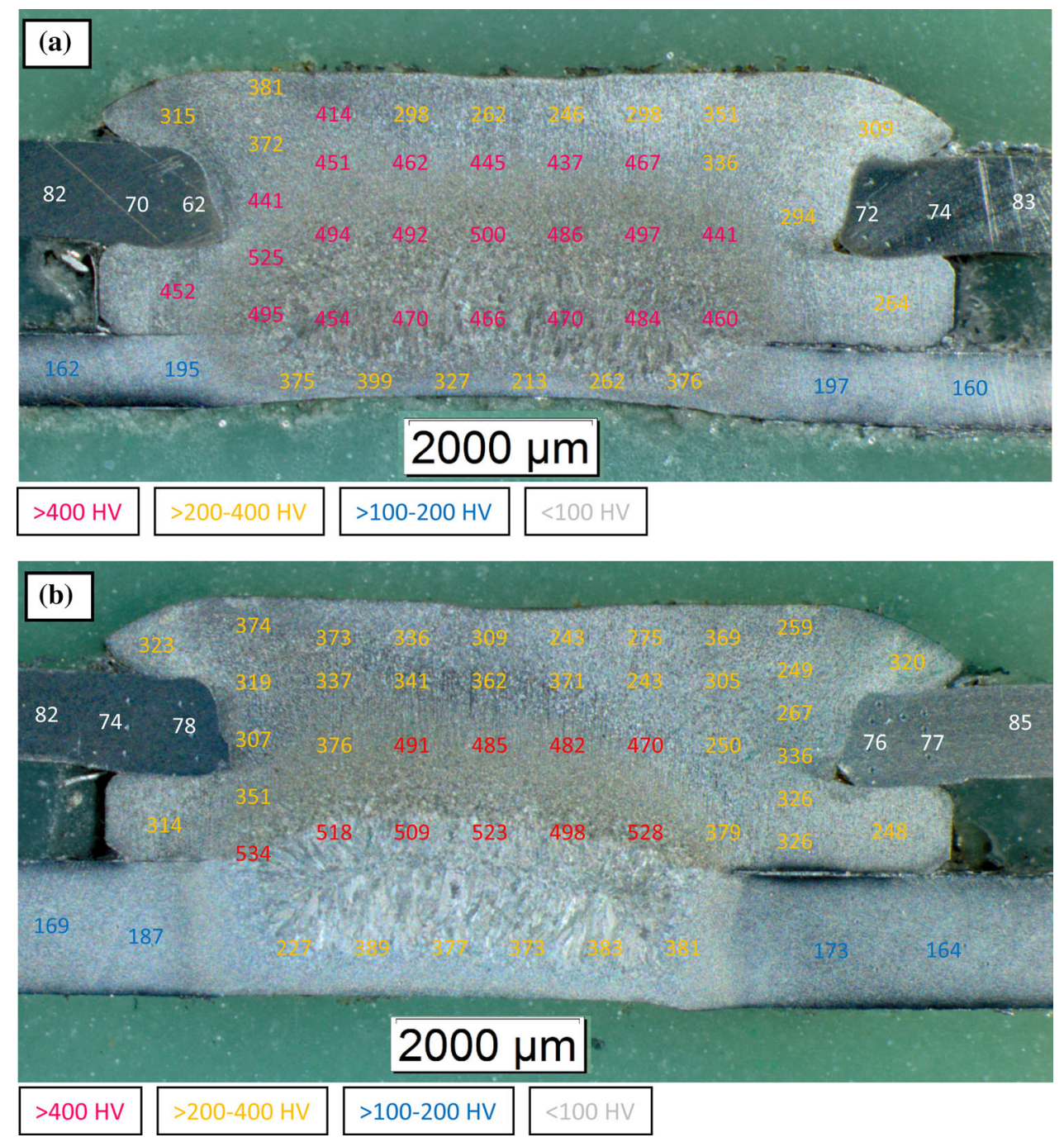

Fig. 17 Micro-hardness tests according to Vickers (units in HV0.2 for Al and HV0.3 for steel) of a fatigue-tested rivet resistance spot welding (RRSW) connection cut from an H-specimen with (a) material combination C1 (0.8 mm steel) and (b) C2 (1.5 mm steel) 


\section{Summary and Conclusion}

Both quasi-static and fatigue tests were conducted on different kinds of steel-Al-specimens that were joined by RRSW and SPR. Static lap-shear tests on one-point shear specimens showed that RRSW has almost equal mechanical properties compared to SPR. RRSW lap-shear specimens with two joining points consisting of a thicker $1.5 \mathrm{~mm}$ CR340 steel showed even a $50 \%$ higher force level at failure in comparison with the corresponding SPR specimens.

For fatigue tests, RRSW joints were found to reach a higher fatigue life than SPR if the steel exhibited sufficient sheet thickness. By contrast, SPR exhibited higher durability with thinner steel sheet thickness. Based on a geometrical and mechanical analysis, the effect of the small gap between the steel and Al sheet metals in RRSW was implicated as a reasonable explanation for this fact. In addition to this effect, the metallurgical analysis showed that for both thin and thick steel sheets, there were distinct hardness changes from weld nugget to base materials so that metallurgical notches were present. The obtained results for the thin steel sheet are in good agreement with state-of-the-art results, which indicate that fatigue loads are more severe to welding-based joints in comparison with mechanical joints. Fatigue-loaded flat lapshear specimens qualitatively showed the same fracture pattern as the 10-point $\mathrm{H}$-specimen. Since the $\mathrm{H}$-specimen can take load-redistribution into account, the SN-curve inclination was slightly higher in comparison with the 1- and 2-point specimens.

In summary, the findings regarding the H-specimen, which is similar to real vehicle structures, revealed that RRSW shows both better quasi-static and fatigue strength in comparison with SPR if thicker steel sheet metal of $1.5 \mathrm{~mm}$ is joined to $1 \mathrm{~mm} \mathrm{Al-}$ sheet metal. In case of $0.8 \mathrm{~mm}$ steel sheet to $1.0 \mathrm{~mm} \mathrm{Al}$, the quasi-static strength of RRSW is better than SPR, and the fatigue strength is lower. For vehicle applications, RRSW can be recommended if thicker steels have to be welded to Al. For thinner steels, the number of RRSW welding points must be increased compared to the SPR design. Since the spot weld distance in vehicle body is usually large enough, it is possible to shorten the distance.

\section{Acknowledgments}

The authors thank the technical support received from the companies Henrob and Dalex and the German Federal Ministry for Economic Affairs and Energy (BMWi) as well as the German Federation of Industrial Research Associations (AiF) for their organizational and financial support. Finally, we thank the unknown reviewers for detailed and helpful comments within the review process.

\section{Funding} DEAL.
Open Access This article is licensed under a Creative Commons Attribution 4.0 International License, which permits use, sharing, adaptation, distribution and reproduction in any medium or format, as long as you give appropriate credit to the original author(s) and the source, provide a link to the Creative Commons licence, and indicate if changes were made. The images or other third party material in this article are included in the article's Creative Commons licence, unless indicated otherwise in a credit line to the material. If material is not included in the article's Creative Commons licence and your intended use is not permitted by statutory regulation or exceeds the permitted use, you will need to obtain permission directly from the copyright holder. To view a copy of this licence, visit http://creativecommons.org/licenses/by/4.0/.

\section{References}

1. K.-I. Mori and Y. Abe, A Review on Mechanical Joining of Aluminum and High Strength Steel Sheets by Plastic Deformation, J. Lightw. Mater. Manuf., 2018, 1, p 1-11. https://doi.org/10.1016/j.ijlmm.2018. 02.002

2. R. Haque, Quality of Self-Piercing Riveting (SPR) Joints from CrossSectional Perspective: A Review, Archiv. Civ. Mech. Eng., 2018, 18, p 83-93. https://doi.org/10.1016/j.acme.2017.06.003

3. G. Meschut, V. Janzen and T. Olfermann, Innovative and Highly Productive Joining Technologies for Multi-Material Lightweight Car Body Structures, J. Mater. Eng. Perform., 2014, 23, p 1515-1523. https://doi.org/10.1007/s11665-014-0962-3

4. X. He, I. Pearsons and K. Young, Self-Pierce Riveting for Sheet Materials: State of the Art, J. Mater. Process. Technol., 2007, 199, p 27-36. https://doi.org/10.1016/j.jmatprotec

5. Z. Ling, Y. Li, Z. Luo, Y. Feng and Z. Wang, Resistance Element Welding of 6061 Aluminum Alloy to Uncoated 22MnMoB Boron Steel, Mater. Manuf. Process., 2016, 31(16), p 2174-2180

6. S. Hong, F. Yan, S.J. Sung, J. Pan, X. Su and P. Friedman, Investigation of Failure Mode and Fatigue Behavior of Flow Drill Screw Joints in Lap-Shear Specimens of Aluminum 6082-T6 Sheets, SAE J. Mater. Manf., 2016, 9(3), p 746-750. https://doi.org/10.4271/2016-01-0501

7. W. Eichlseder and R. Schöneburg, Anforderungen an den Leichtbau im Fahrzeug, Leichtbau in der Fahrzeugtechnik (The Technical Motivation for Lightweight Design), 2nd ed., H. Friedrich Ed., Springer Vieweg Verlag, Wiesbaden, 2017, p 125-182

8. D. Li, A. Chrysanthou, I. Patel and G. Williams, Self-Piercing Riveting-A Review, Int. J. Adv. Manuf. Technol., 2017, 92, p 17771824. https://doi.org/10.1007/s00170-017-0156-x

9. Y. Abe, T. Kato and K.-I. Mori, Self-Piercing Riveting of High Tensile Strength Steel and Aluminium Alloy Sheets Using Conventional Rivet and Die, J. Mater. Process. Technol., 2009, 209, p 3914-3922. https://d oi.org/10.1016/j.jmatprotec.2008.09.007

10. I. Stone, B. McKay and Z. Fan, Influence of Rivet Tip Geometry on the Joint Quality and Mechanical Strengths of Self-Piercing Riveted Aluminum Joints, Mater. Sci. Forum, 2013, 765, p 746-750

11. D. Li, L. Han, M. Thornton and M. Shergold An Evaluation of Quality and Performance of Self-Piercing Riveted High Strength Aluminium Alloy AA6008 for Automotive Applications, SAE Technical Paper, 2010, 01-0223, https://doi.org/https://doi.org/10.4271/2010-01-0223

12. S. Kang and H. Kim, Fatigue Strength Evaluation of Self-Piercing Riveted A1-5052 Joints Under Different Specimen Configurations, Int. J. Fatig., 2015, 80, p 58-68. https://doi.org/10.1016/j.ijfatigue.2015. 05.003

13. K. Mori, Y. Abe and T. Kato, Mechanism of Superiority of Fatigue Strength for Aluminum Alloy Sheets Joined by Mechanical Clinching 
and Self-Pierce Riveting, J. Mater. Process. Technol., 2012, 212, p 1900-1905. https://doi.org/10.1016/j.jmatprotec.2012.04.017

14. M. Reinstettel, "Laboruntersuchung zur Prozessstabilität beim NietClinchen (Investigation of Process Stability of Rivet-Clinching)", Ph.D. Thesis. Technical University of Chemnitz, 2007, in German

15. A. Chergui, "Beitrag zur ermüdungsgerechten Auslegung stanzgenieteter Aluminium-Leichtbaukonstruktionen (On the Fatigue-optimised Design of Self-piercing-riveted Aluminum-Lightweight Design Structures)", Ph.D. Thesis, University of Paderborn, 2004, in German

16. A. Gay, F. Lefebvre, S. Bergamo, F. Valiorgue, P. Chalandron and P. Michel, Fatigue Performance of a Self-Piercing Rivet Joint Between Al and Glass Fiber Reinforced Thermoplastic Composite, Int. J. Fatig., 2016, 83, p 127-134. https://doi.org/10.1016/j.ijfatigue.2015.10.004

17. X. Sun, E. Stephens and M. Khaleel, Fatigue Behaviors of Self-Piercing Rivets Joining Similar and Dissimilar Sheet Metals, Int. J. Fatig., 2007, 29, p 370-386. https://doi.org/10.1016/j.ijfatigue.2006.02.054

18. A. Krause, R. Chernenkoff, A Comparative Study of the Fatigue Behavior of Spot Welded and Mechanically Fastened Aluminum Joints, SAE technical paper series, 1995, 95070. https://doi.org/http s://doi.org/10.4271/950710

19. G.S. Booth, C.A. Olivier and S.A. Westgate, Self-Piercing Riveted Joints and Resistance Spot Welded Joints in Steel and Aluminum, SAE Technical Paper, 2000, 01-2681. doi:https://doi.org/10.4271/2000-012681

20. A. Galtier and J. Gacel, Fatigue Behavior of Mechanical Joining for HSS Grades, SAE Technical Paper 2002, 01-1998. https://doi.org/h ttps://doi.org/10.4271/2002-01-1998

21. DIN EN ISO 14324, Resistance spot welding-Destructive tests of welds-Method for the Fatigue Testing of Spot-Welded Joints, 2003

22. O. Hahn and A. Rhode, Stanznieten von Aluminium mit Stahl mittels Halbhohlniet (Self-Piercing Riveting of Aluminum and Steel Sheet), FAT-Schriftenreihe Nr. 148. Frankfurt, Forschungsvereinigung Automobiltechnik FAT, 1999, in German

23. O. Hahn, H. Hanselka, J. Toelle and H. Schmidt, Entwicklung einer Methode zur vergleichbaren Bewertung von Schwingfestigkeitsversuchen gefügter Stahlbleche in Abhängigkeit ihres Versagensverhaltens (Developing a Methodology for a comparative Evaluation of the Fatigue Behavior of joined Steel Sheets depending on the Failure Mode), FAT Schriftenreihe Nr. 221, Frankfurt, Forschungsvereinigung Automobiltechnik FAT, 2009, in German
24. H. Hanselka, K. Stoerzel and T. Bruder, Überlasten und ihre Auswirkungen auf die Betriebsfestigkeit widerstandspunktgeschweißter Feinblechstrukturen (Overload an its Influence on the Durability of spot-welded metal sheets), FAT-Schriftenreihe 239, Berlin, Forschungsvereinigung Automobiltechnik FAT, 2012, in German

25. DIN EN ISO 18592, Resistance welding-Destructive testing of welds-Method for the Fatigue Testing of Multi-Spot-Welded Specimens, 2009

26. X.F. Fang and F. Zhang, Hybrid Joining of a Modular Multi-Material Body-in-White Structure, J. Mater. Process. Technol., 2020, 275, p 116351. https://doi.org/10.1016/j.jmatprotec.2019.116351

27. Arcelor Mittal, High- Strength Low-Alloy (HSLA) Steels For Cold Forming, https://automotive.arcelormittal.com/products/flat/HYTSS/H SLA, 2020, Accessed 25 March 2020

28. L. Han, M. Thornton, D. Li and M. Shergold, Effect of Setting Velocity on Self-Piercing Riveting Process and Joint Behavior for Automotive Applications, SAE Technical Paper, 2010, 01-0966. https://doi.org/h ttps://doi.org/10.4271/2010-01-0966

29. DIN EN ISO 14273, Resistance welding-Destructive testing of welds-Specimen Dimensions and Procedure for Tensile Shear Testing Resistance Spot and Embossed Projection Welds, 2001

30. DVS/EFB Leaflet 3480-1, Testing of Properties of Joints-Testing of Properties of Mechanical and Hybrid (Mechanical/Bonded) Joints, 2007

31. F. Zhang, "Entwicklung eines neuen Widerstandsnietschweißverfahrens zur flexiblen und wirtschaftlichen Fertigung der Karosserie in der Al-Stahl-Mischbauweise (Development of a novel Resistance Rivet Spot Welding Technique for Flexible Car Body Structures in AlSteel Multi-Material Design)", Ph.D. Thesis, University of Siegen, 2020

32. M. Pouranvari and S.P.H. Marashi, Failure Mode Transition in AHSS Resistance Spot Welds. Part I. Controlling Factors, Mater. Sci. Eng.: A, 2011, 528(29-30), p 8337-8343. https://doi.org/10.1016/j.msea.2011. 08.017

Publisher's Note Springer Nature remains neutral with regard to jurisdictional claims in published maps and institutional affiliations. 